\title{
Genomic organization and splicing evolution of the doublesex gene, a Drosophila regulator of sexual differentiation, in the dengue and yellow fever mosquito Aedes aegypti
}

Marco Salvemini ${ }^{1 \dagger}$, Umberto Mauro $^{1,2 \dagger}{ }^{+}$, Fabrizio Lombardo ${ }^{3}$, Andreina Milano $^{1}$, Vincenzo Zazzaro ${ }^{1}$, Bruno Arcà ${ }^{3,4}$, Lino C Polito ${ }^{1,5}$, Giuseppe Saccone ${ }^{1 *}$

\begin{abstract}
Background: In the model system Drosophila melanogaster, doublesex $(d s x)$ is the double-switch gene at the bottom of the somatic sex determination cascade that determines the differentiation of sexually dimorphic traits. Homologues of $d s x$ are functionally conserved in various dipteran species, including the malaria vector Anopheles gambiae. They show a striking conservation of sex-specific regulation, based on alternative splicing, and of the encoded sex-specific proteins, which are transcriptional regulators of downstream terminal genes that influence sexual differentiation of cells, tissues and organs.
\end{abstract}

Results: In this work, we report on the molecular characterization of the $d s x$ homologue in the dengue and yellow fever vector Aedes aegypti (Aeadsx). Aeadsx produces sex-specific transcripts by alternative splicing, which encode isoforms with a high degree of identity to Anopheles gambiae and Drosophila melanogaster homologues. Interestingly, Aeadsx produces an additional novel female-specific splicing variant. Genomic comparative analyses between the Aedes and Anopheles dsx genes revealed a partial conservation of the exon organization and extensive divergence in the intron lengths. An expression analysis showed that Aeadsx transcripts were present from early stages of development and that sex-specific regulation starts at least from late larval stages. The analysis of the female-specific untranslated region (UTR) led to the identification of putative regulatory cis-elements potentially involved in the sex-specific splicing regulation. The Aedes dsx sex-specific splicing regulation seems to be more complex with the respect of other dipteran species, suggesting slightly novel evolutionary trajectories for its regulation and hence for the recruitment of upstream splicing regulators.

Conclusions: This study led to uncover the molecular evolution of Aedes aegypti dsx splicing regulation with the respect of the more closely related Culicidae Anopheles gambiae orthologue. In Aedes aegypti, the dsx gene is sexspecifically regulated and encodes two female-specific and one male-specific isoforms, all sharing a doublesex/mab3 (DM) domain-containing N-terminus and different C-termini. The sex-specific regulation is based on a combination of exon skipping, 5' alternative splice site choice and, most likely, alternative polyadenylation. Interestingly, when the Aeadsx gene is compared to the Anopheles dsx ortholog, there are differences in the in silico predicted default and regulated sex-specific splicing events, which suggests that the upstream regulators either are different or act in a slightly different manner. Furthermore, this study is a premise for the future development of transgenic sexing strains in mosquitoes useful for sterile insect technique (SIT) programs.

\footnotetext{
* Correspondence: giuseppe.saccone@unina.it

† Contributed equally

'Department of Biological Sciences - Section of Genetics and Molecular

Biology. University of Naples "Federico II" - Italy

Full list of author information is available at the end of the article
} 


\section{Background}

DSX proteins are part of the Dmrt (doublesex and mab3-related transcription factor) family, a structurally and functionally conserved group of zinc-finger proteins with relevant roles in sex determination and sexual differentiation throughout the animal kingdom [1,2].

In Drosophila melanogaster and many other dipteran species, $d s x$ orthologues produce sex-specific transcripts through alternative splicing, which encode two highly conserved isoforms that share a common $\mathrm{N}$-terminus containing a zinc-finger domain (named DM domain) [3]. The DSX sex-specific isoforms are responsible for the proper sexual differentiation of somatic tissues and the gonads [4-7]. The female-specific splicing of the $d s x$ pre-mRNA is under the control of the conserved Transformer (which is female-specifically expressed) and Transformer-2 (a non-sex-specific auxiliary factor) splicing regulators in Drosophila and other dipteran species, such as Ceratitis capitata [8,9] and other Tephritidae species [10,11], Musca domestica (Muscidae) [12,13] and Lucilia cuprina (Calliphoridae) [14]. Sequence comparisons led to the identification of key splicing regulatory elements, the so-called TRA/TRA-2 binding sites, conserved in different Drosophila species and in the female-specific exon of these $d s x$ orthologous genes from non-Drosophilidae families. In addition to the sexspecific regulation, the functions exerted during sexual development by the two DSX isoforms are evolutionarily conserved. For example, ectopic expression of either the male-specific or the female-specific isoform of Musca domestica $\left(\mathrm{MdDSX}^{\mathrm{M}}\right.$ and $\mathrm{MdDSX}{ }^{\mathrm{F}}$ ) [15], Ceratitis capitata $\left(\mathrm{CcDSX}^{\mathrm{M}}\right)$ [16] and Anastrepha obliqua (AoDSX ${ }^{\mathrm{M}}$ and $\mathrm{AoDSX}^{\mathrm{M}}$ ) [17] into Drosophila transgenic flies caused a partial masculinization of XX and a partial feminization of XY individuals, respectively.

In the mosquito Anopheles gambiae (Diptera, Culicidae), a $d s x$ ortholog was previously isolated, and it maintains sex-specific regulation by alternative splicing and putative TRA/TRA-2 binding sites in the femalespecific exon $[18,19]$. However, despite the availability of a genome sequence, it is still unclear whether $d s x$ is also under the control of the TRA-related and TRA-2 orthologous proteins in this species, as in the Drosophila, Tephritidae, Muscidae and Calliphoridae species.

Outside the order Diptera, $d s x$ orthologues have been isolated in the lepidopteran Bombyx mori (Bmdsx) [20] and in the hymenopteran honeybee Apis mellifera $(A m d s x)[21,22]$ and the parasitic wasp Nasonia vitripennis ( $N v d s x)$ [23]. In these species, only a partial conservation of dipteran $d s x$ features was reported, with sex-specific alternative splicing conserved, and different cis-acting elements identified. In Bombyx mori, $d s x$ plays an essential role in silkworm sexual development and, when compared to Drosophila, interestingly shows a reversed pattern of default versus regulated sex-specific splicing [24] (for a reviews see [3]). Sex-specific splicing of the honeybee Apis mellifera doublesex gene revealed 300 million years of conservation at the bottom of the insect sex-determination pathway, confirming its key role in sexual differentiation [21,22]. Finally, in the other hymenopteran, Nasonia vitripennis, the availability of a gynandromorphic line led to the first demonstration of a direct functional association of the $d s x$ orthologue with somatic sex differentiation in Hymenoptera [23].

The mosquito Aedes aegypti is the most important, global arthropod vector for the yellow fever and dengue viruses. Ae. aegypti is considered one of the best mosquito species for laboratory culture and has been used for detailed laboratory studies in various fields [25]. Furthermore, the Aedes genome and transcriptome sequences have been partially determined [26]. However, the genetic control of the Aedes sex determination is still to be clarified. In this species, the primary signal is different from that in D. melanogaster, where the X-chromosome dosage controls sex differentiation [27], and An. gambiae, where an heteromorphic $\mathrm{Y}$ chromosome contains a male-determining factor(s) that dominantly induces male development by its presence in an XX/XY system [28]. In Aedes, as observed for other culicine mosquitoes, heteromorphic sex chromosomes are absent, and sex is controlled by an autosomal locus that carries a male-determining gene, $\mathrm{M}$, acting as a dominant male determiner [29].

An Aedes aegypti orthologue for Drosophila doublesex was previously identified by an in silico analysis of the genome, in addition to orthologues of other Drosophila genes potentially involved in sex determination and sexual differentiation, such as transformer-2, fruitless, dissatisfaction and intersex [26].

Here we present the genetic and genomic characterization of the Aedes aegypti $d s x$ ortholog, its sex-specific expression analysis during development and a comparative evolutionary analysis. We show that Aedes DSX sex-specific isoforms are produced by sex-specific alternative splicing mechanisms with slight differences compared to other species. The Aedes $d s x$ gene encodes indeed a novel second female-specific DSX isoform, by an exon skipping mechanism. Interestingly different putative splicing regulatory sequences have been found within the sex-specifically regulated Aedes $d s x$ region, suggesting a possible model of its splicing regulation by upstream factors. Furthermore, our study opens the possibilities to identify the downstream targets of DSX in Aedes, which are still not well defined even in the model system Drosophila melanogaster, and to identify upstream splicing regulators of the Aedes sex determination cascade, which have not yet been isolated possibly conserved also in the other mosquitoes An. gambiae, vector of malaria disease. 


\section{Results and Discussion}

\section{Isolation and molecular characterization of the Aeadsx} gene

The molecular cloning of the Aedes aegypti $d s x$ gene (Aeads $x$ ) was performed by combining a classical PCRbased approach with the available bioinformatic and genomic tools. The later used the non-sex-specific region of the Anopheles gambiae DSX protein (236 aa) as a virtual probe for a BLASTP search of the Ensembl Ae. aegypti AaegL1 genomic database (http://www. ensembl.org/) (see Methods for further strategy details). A putative male-specific cDNA sequence was then obtained by EST analysis, using An. gambiae $d s x$ malespecific nucleotide sequences (kindly provided by Pannuti A. and Lucchesi J., Emory University - USA, prior publication). Using specific primer pairs for the putative male-specific EST and common genomic sequences, we performed an RT-PCR analysis on RNA samples extracted from adult sexed Ae. aegypti mosquitoes. With this approach, we successfully amplified sex-specific products of the Aeadsx gene, with two female-specific products of $1.5 \mathrm{~kb}$ and $2.0 \mathrm{~kb}$ and a male-specific product of $1.0 \mathrm{~kb}$ (Figure 1B). cDNA products were cloned and sequenced, and their conceptual translation of incomplete ORFs and comparison with DSX isoforms revealed striking conservation of the DSX DM domain and the female-specific carboxy domain encoded by the $2.0 \mathrm{~kb}$ product. Through 5'-3' RACE PCR, we next obtained longer cDNAs containing fully open reading frames. The 3 cDNA clones were named as Aeads $x^{F 1}$ (2846 bp), Aeadsx $x^{F 2}$ (2384 bp) and Aeadsx ${ }^{M 1}$ (1918 bp), which encoded three Aedes aegypti DSX isoforms, DSX ${ }^{\mathrm{F} 1}$ (278 aa), $\operatorname{DSX}^{\mathrm{F} 2}$ (267 aa) and $\operatorname{DSX}^{\mathrm{M} 1}$ (548 aa), respectively. The alignment of the Aeadsx cDNA sequences with the Aedes corresponding genomic sequence was used to define the exon/intron organization and the alternative splicing events leading to distinct sex-specific mRNAs (Figure 1A).

These data confirmed the identification of the $A e$. aegypti $d s x$ gene, which produced sex-specific transcripts by alternative splicing.

\section{Aeadsx genomic organization and evolution}

The Aeadsx gene spans a very large $450 \mathrm{~kb}$ long genomic region, located in supercontig 1.370, and consists of at least eight exons with seven introns that vary markedly in length from 208 to $274,879 \mathrm{bp}$.

The first four Aeadsx exons (2-3a-3b-4) are nonsex-specific and encode the 248 amino acid common $\mathrm{N}$-terminus region of AeaDSX proteins. The four exons are followed by two alternatively spliced female-specific exons (5a-5b), encoding 30 and 19 amino acid sequences, respectively, and two male-specific exons (6-7), the first one encoding the male-specific protein domain of 300 aa and the second one constituting the 3' UTR sequence (Figure 1A).

The first four Aeadsx exons correspond by homology to the second, third and fourth exons of the Angdsx, suggesting that we missed the real first Aeadsx exon (Figure 2). Interestingly, some of the Aedes $d s x$ cDNAs exhibit in this second exon the presence of a nonsex-specific alternative splicing event by intron retention of a short coding 63-nt region. The corresponding encoded 21-amino acid tract is highly conserved in AngDSX isoforms (Figure 1 and 3A) but lacks any conservation with DSX isoforms from other dipteran species (data not shown). This finding suggests that this short region is used in vivo and should play a functional role that seems to be under positive natural selection.

Because the N-termini of the encoded Anopheles and Aedes DSX proteins are highly conserved, starting from the first putative methionine, this selective constraint suggests that the $d s x$ translation start site is conserved in both species. As in the 5' UTR of the isolated cDNA there is lack of sequence corresponding to the Angdsx exon 1, and additional upstream genomic sequences of Aeads $x$ are likely still to be identified, including the promoter region.

The Aedes exon 3a and 3b exhibit a low level of amino acid conservation. In particular, exon 3a seems to correspond to the unique Anopheles exon 3 (see alignment in Figure 3). The short exon $3 \mathrm{~b}$ encodes 16 amino acids with no homology to DSX or other known proteins and it constitute an event of exon gain. Exon 5 in Aedes is separated into two exons ( $5 \mathrm{a}$ and $5 \mathrm{~b}$ ). These exons (461 bp and $465 \mathrm{bp}$, respectively) maintain the female-specific alternative splicing regulation (Figure 2). Interestingly, it seems that $d s x$ underwent to either intron gain in the Aedes or intron loss in the Anopheles lineages.

Finally, Aedes exons 6 and 7 (1.1 kb and $0.5 \mathrm{~kb})$ correspond to the Anopheles male-specific exons 6 and 7 . The exon 6 encodes in both species the male-specific DSX portion and includes part of the 3' UTR. The exon 7 corresponds to the remaining 3' UTR.

The Aedes $d s x$ exons show variable sequence similarity, conserved exon-intron junctions, an exon gain (3b exon) and an intron gain (intron between $5 \mathrm{a}$ and $5 \mathrm{~b}$ exons) events and hence partial structural correspondence to the Anopheles $d s x$ exons. In particular, with respect to the Anopheles homologue, Aeadsx common exons 2 and 4 are largely conserved in size and content, while sexspecifically regulated exons as well as exons $3 \mathrm{a}$ and $3 \mathrm{~b}$ share a lower level of sequence identity. On the contrary, an extensive divergence in intron structure (intron position and length) was observed that reflects overall genomic differences between the species (Figure 2). The $d s x$ gene in An. gambiae is contained within an $85-\mathrm{kb}$ genomic region; 


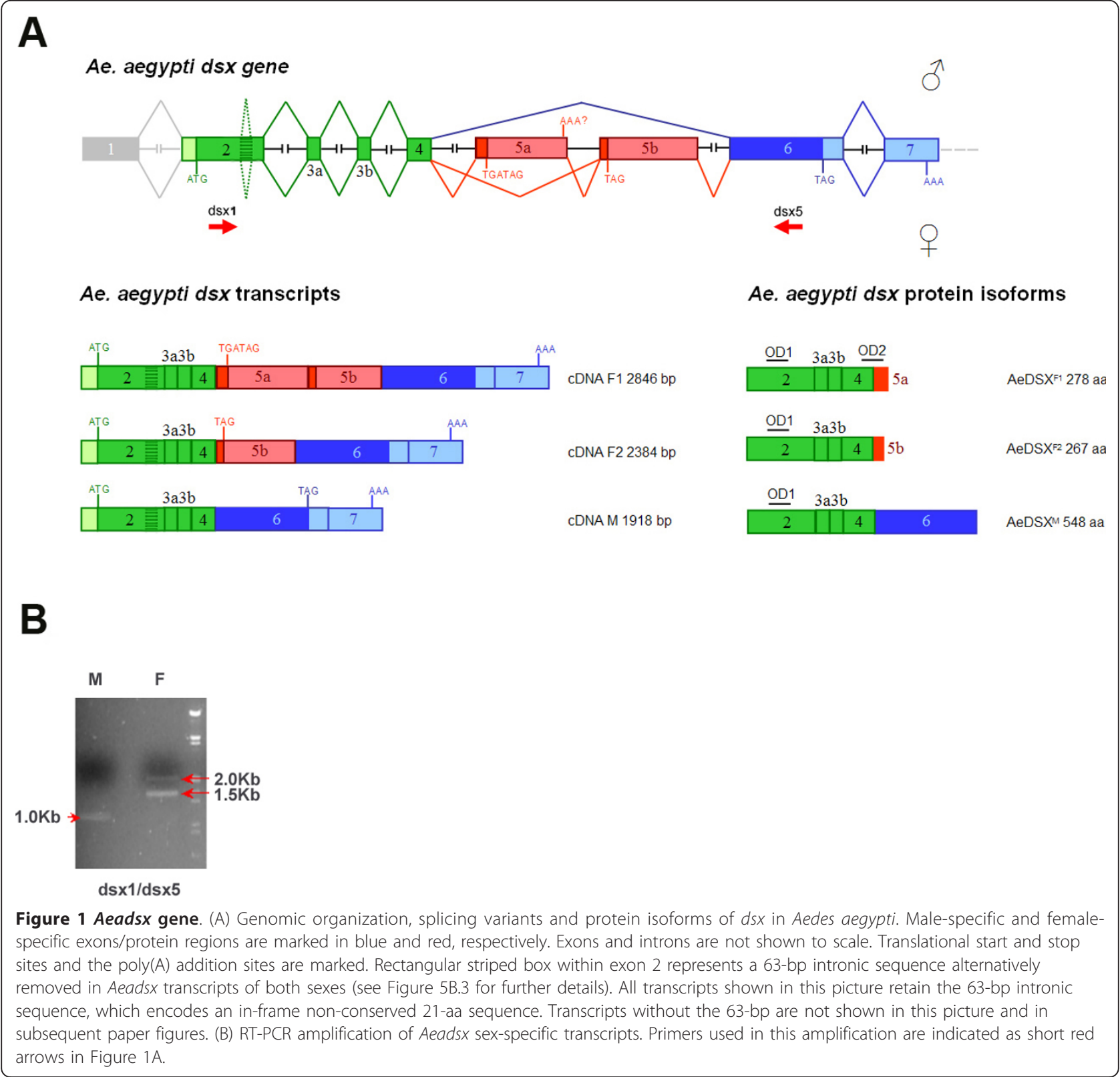

therefore, the corresponding Ae. aegypti genomic sequence is approximately 5.3 -fold larger. This difference is due to the presence of very large introns in the Ae. aegypti homologue, with an average intron size of 64 $\mathrm{kb}$ in contrast to the observed average intron size for Angdsx (15 kb). This is undoubtedly reflective of the overall differences in genome organization of the two species because the $A n$. gambiae genome size is about $243 \mathrm{Mb}$, while Ae. aegypti is about five-fold larger at about $1.31 \mathrm{~Gb}$. Most of this difference is due to the high frequency of repetitive sequences in the Ae. aegypti genome [26].

An analysis of Aeadsx introns with CENSOR software (http://www.girinst.org/censor/index.php) [30] revealed the presence of multiple copies of repetitive elements, the most abundant of which are the NON-LTR/Jockey LINE-1_AA elements [31], detected in 34 copies, and the NON-LTR/SINE Feilai element [32], detected in 30 copies (Additional file 1, Table S1). Interestingly, the comparative analysis of CENSOR outputs of Aeadsx introns revealed that two out of three sex-specifically regulated introns, the short intron 5 (208 bp long) and intron 6 (10392 bp long), significantly deviate in the number of repetitive elements per $\mathrm{kb}$ (indicated as $\mathrm{NoRE} / \mathrm{kb}$ ) and in the percentage of nucleotides of repetitive elements relative to intron nucleotides (indicated as REbp). Aeads $x$ intron 5 contains no repetitive element at 


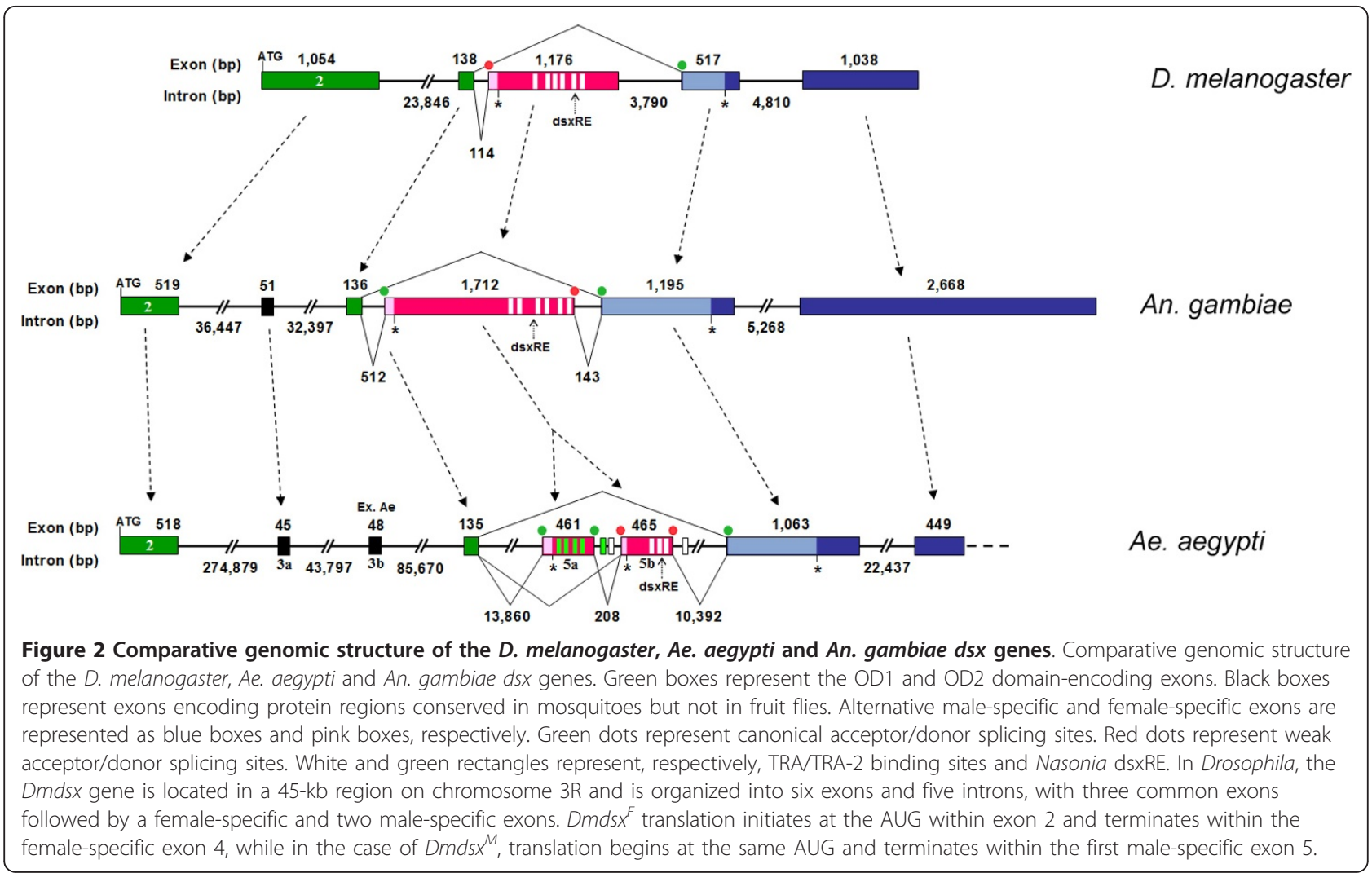

all, while Aeadsx intron 6 presents a NoRE/kb value of 0.6 and a REbp value of $7 \%$ with respect to the mean NoRE/kb and REbp values of non-sex-specific introns, which were 1.13 and 18\%, respectively (Additional file 2, Figure S1). This finding suggests that there may have been positive selective pressure on these two intronic regions against repetitive elements to preserve sex-specific alternative splicing regulation.

We used the entire supercontig $1.370 d s x$-containing region of Ae. aegypti to analyze the presence and nature of genomic microsynteny between Ae. aegypti and $A n$. gambiae. We compared the amino acid sequences of all putative genes in Aedes supercontig 1.370 with putative genes of the syntenic region in An. gambiae obtained from the Ensembl precomputed tBLAT DNA-DNA comparison for the two insect species.

Gene density in these regions was apparently higher (twice) in An. gambiae relative to Ae. aegypti. The relative synteny quality, expressed as a percentage and calculated by dividing the number of conserved genes in both syntenic regions by the total number of genes in both regions [33], was $62 \%$. Out of a total of 16 genes in these regions, 10 homologues were found including $d s x$. Interestingly, microsynteny of the prospero gene with the $d s x$ gene, previously described also for Anopheles gambiae, Apis mellifera and Tribolium castaneum
[23], was not conserved in the Aedes aegypti $d s x$ containing region (Additional file 3, Figure S2). This finding suggests that a chromosomal rearrangement may have occurred after the split between the two species, bringing the Aedes prospero gene into a different genomic position outside of supercontig 1.370 that is not yet mapped on any Aedes chromosome. A putative Aedes prospero gene (AAEL002769) is located in supercontig 1.67, and a mapped chromosome position is not yet available for this supercontig.

In Aedes aegypti, a putative gene (AAEL009111) encoding a phosphodiesterase is located in Aeadsx intron 2 (position $918233-980385$ of supercontig 1.370) in the opposite direction of transcription with respect to Aeadsx. The Anopheles homologue of this gene (AGAP004054) is located downstream of the prospero gene in the Angdsx-containing microsyntenic region, in the opposite direction of transcription with respect to the Aedes counterpart. In this case a rearrangement, occurred during evolution, moved the gene from one position nearby the $d s x$ gene into the gene itself or vice versa.

\section{Comparison of AeaDSX isoforms}

The alignment of AeaDSX isoforms with the DSX isoforms of D. melanogaster and An. gambiae is presented 


\section{A) Common region}

\begin{tabular}{|c|c|}
\hline & OD1 \\
\hline D.melanogaster & 1 MVSEENWNSDTMSD SDMIDSKNDVCGGASSSSGSS IS PRTPPNCARCRNHGLKITLKGHKRYCKFRYCTCEKCRLTADRQR \\
\hline An. gambiae & 1 MVSQDRW-AEAMSDS-GYDSRTDGNG-ASSSCNNSLNPRTPPNCARCRNHGLKIGLKGHKRYCKYRTCHCEKCCLTAERQR \\
\hline \multirow[t]{2}{*}{ Ae.aegypti } & W-MVKMSEA-GYDNRADGSG-ASSS---SLNPRTPPNCARCRNHGHKIGLKGHKRYCKYRNCTCEKCCLTAERQR \\
\hline & * $\quad$ * \\
\hline D.melanogaster & 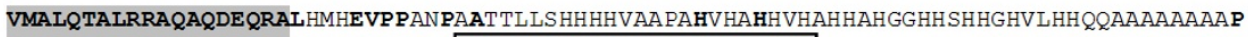 \\
\hline An. gambiae & VMALQTALRRAQTQDEQRALNE GEVP PE-PVAN IH IPKLSELKDLKHNMI HNSQ_---------PRS-FDCDS STGSMASAP \\
\hline Ae.aegypti & $\begin{array}{l}\text { VMALQTALRRAQTQDEQRLLVDGEVPAE-P VHSLQIPKLSDLK----EMIHNSQQ } \\
\text { * }\end{array}$ \\
\hline melanogaster & SAPASHLGGSSTAASS IHGHAHAHHVHMAAAAAASVAQHQHQSH PH SH HHHH QNHHQHPHQQPAT QTALRSP PHSD------- \\
\hline An. gambiae & ------- GTS --------------------- SVPLT IHRRS PG -- VP HHVAEPQH ---------------------- \\
\hline Ae.aegypti & -------- GSS ---------------------- LVT LS QHRRS PCSAASVH PSEA Q QN ------------------------ \\
\hline D.melanogaster & HGGSVGPATSSSGGGAPSSSNAAAATSSNGSSGGGGGGGGGSSGGGAGGGRSSGTSVIT SADHHMTTVPTPAQSLEGSCDSSS \\
\hline An. gambiae & LGATHSCVS \\
\hline Ae.aegypti & OD2 \\
\hline D.melanogaster & PSPSSTSGAAILPISVSVNR---------------KNGANVPL--------GRDVFLDYCQKLLEKFRY PWELMPLMYVILKD \\
\hline An.gambiae & PEP-----VNLL $-----------------------\overline{\mathbf{T}}--------------$ P DELVKRAQWLLEKLGY PWEMMPLMYVILKS \\
\hline Ae.aegypti & PEP-----GNMV-------------------PVGPHMRVQHHGPDSGT DDELVKRSQWLLEKLRY PWEMMPLMYVILKG \\
\hline D.melanogaster & ADANIEEASRRIEE 397 \\
\hline An. gambiae & ADGDVQKAHQRIDE 235 \\
\hline Ae.aegypti & ADGDVNKARQRIDE 248 \\
\hline
\end{tabular}

\section{B) F1 Female-specific region}

$\begin{array}{llll}\text { D.melanogaster } & 398 \text { GQYVVNEYSRQHNLNIYDGGELRNTTRQCG } & 427 \\ \text { An.gambiae } & 236 \text { GQAVVNEYSRLHNLNMFDGVELRNTTRQSG } & 265 \\ \text { Ae.aegypti } & 249 \text { GQAVVNEYSRLHNLNMFDGVELRSTTRQSG } & 278\end{array}$

\section{C) F2 Female-specific region}

An.gambiae EXON5 (1712bp) +766bp TGTACATACGGTTCGÄGATAACTTTGACCTGCAGCCGTTCTGGGGCTGTCACGTGTAG Ae.aegypti ExON5b ( $465 \mathrm{bp}) \quad+2 \mathrm{bp}$ TGCAAATGCTGTTTAACGATAATAGCGACATGCAGCCATTCTGGGGCTACCACGTGTAG
An. gambiae
Ae.aegypti DSXF2
\begin{tabular}{lllllllllllll} 
& Y & I & R & F & E & D & N & F & D & L & Q & P \\
\hline & Q & M & L & F & N & D & N & S & D & M & Q & P
\end{tabular}
$\begin{array}{llll}\text { F } & \text { W } & \text { G } & \text { C } \\ \text { F } & \text { W } & \text { G } & \text { Y }\end{array}$
$\begin{array}{lll}H & V & * \\ H & V & *\end{array}$

\section{D) Male-specific region}

D.melanogaster An. gambiae Ae.aegypti

D. melanogaster An. gambiae Ae.aegypti

D.melanogaster An. gambiae Ae.aegypti

D.melanogaster An. gambiae Ae.aegypti

D. melanogaster An. gambiae

Ae.aeqypti
$398----1$
236
24

-------SSGT GCDRDDGDC IT FDDSASVVRATHASRSATRMSRGRSRSQTKRYSQTVESTNAPSRS PGPDEEP SVYKSLAEAASKM TTDD--------------EEVMYEKRSPKS IE STE LRCRLEEALHSGAAAAAEE PLAGGS GS HWKRESFGSTEEI P

SR---------------PGSSNGTVHSAAS----------PTMVTTMATTSST PT LSRRQ-----------ARSF I PARE PEDLHTTT HKSPERE DNPSQPYEAYLESVRRSKKSF PHKDAEGVTESAEDCYDKEKEHRI PYSLPKST FDR AR--------- PAHSEPE-DNGFENGLEAHQSHI LHS IHRNVS PKADIAVPS TSAAAAVAEE $Q^{----P A P P K N S E P}$

LDLLKKPNGLPFPMYKYNELEANNFPLPLLLPGLEAVNRTLYTAHFPTHLLPSSLYPPVSSESTTAP IFHTHFLGYQPQM LNLEKRSHPLPG----FEQVPASALAFPFPR---------HPAE LMQFLLP---YPPIFT-------- - QFGVHP PPR

--------

QLPHVEPFYRKEQQQQQLQQTLAEPKEQTTSSSPSNNRLTPPKGTFFYASAVENSLTAHQAS--IATIH 622

IYNDEASI YRKDL P-------------SDSRPPSLSRT SP PEVPSMYHPSRVDPSHSHQSSAPVASIH 548

Figure 3 Multiple sequence alignment of DSX homologues. Protein sequence alignment of DSX isoforms in Drosophila melanogaster, Anopheles gambiae and Aedes aegypti. The sequences are divided into a region that is common to males and females (A), a first female-specific region (B), a second female-specific region (C) and a male-specific region (D). The amino-terminal DNA binding (OD1) and oligomerization domains (OD2) are boxed in grey. The asterisk $\left(^{*}\right)$ indicates six amino acids whose replacements has been shown to abolish DNA-binding activity in D. melanogaster; $\left(^{* *}\right)$ double asterisks indicate the three amino acids specific for the DSX DM domain. Intron positions are indicated by solid triangles. The amino acid stretch marked in rectangular box corresponds to the 63-bp sequence removed in some but not all Aeadsx transcripts. This event leads to the in-frame deletion of the indicated 21-amino acid tract (see Figure 5B.3 for further details). Also the conserved removed amino acid stretch of An. gambiae is marked in rectangular box. Bold letters indicate amino acid identity in the homologous proteins. Gaps were introduced in the alignments to maximize similarity. The comparison of protein sequences was performed using Clustal-W (1.82). 
in Figure 3. Drosophila DSX proteins essentially contain two domains, OD1 and OD2, which serve as interfaces for protein and DNA interactions $[4,34]$. The nonsex-specific OD1 is composed of an atypical zinc-finger domain (DM), which directly binds to target sequences on the DNA. OD2 is an oligomerization domain that has a common region and a female-specific portion. A sequence alignment of Aeadsx isoforms shows a high degree of sequence conservation in the $\mathrm{N}$-terminus up to the unique OD1 domain and the common part of the OD2 domain. Furthermore, within the OD1 domain, we have found full conservation of the six residues $(\mathrm{C}, \mathrm{H}$, $\mathrm{H}, \mathrm{C}, \mathrm{C}, \mathrm{R}$ ) essential for DNA-binding activity in D. melanogaster [35] and the three residues (E, T, Q) recently identified to be specific to the insect DSX DM domain [23]. These nine residues were also conserved in An. gambiae DSXs [19].

The region that links OD1 and OD2 is less conserved in Aedes and Anopheles and lacks the low complexity region from Drosophila that contains a large number of histidine, glycine and alanine residues (Figure 3A).

The C-terminal region of DSX ${ }^{\mathrm{F}}$ proteins shows a very high degree of sequence conservation among different insects, and this region in Aedes aegypti, encoded by the Aeads $x^{F 1}$ transcript, is also very highly conserved (Figure $3 \mathrm{~B}$ ).

The predicted protein encoded by the Aeads $x^{F 2}$ transcript differs from the AeaDSX ${ }^{\mathrm{F} 1}$ protein due to a short 19-aa alternative female-specific C-terminus with no obvious similarity to other DSX isoforms. However, the corresponding nucleotide sequence encoding the short AeaDSX ${ }^{\mathrm{F} 2} \mathrm{C}$-terminal region is highly conserved in the untranslated region of the Anopheles gambiae femalespecific $d s x$ exon 5 (Figure $3 C$ ). This strong sequence conservation of an untranslated region of the $A n$. gambiae $d s x$ gene could be related to either the use of this region for alternative splicing events (still to be identified in Anopheles) leading to a coding frame in Anopheles, as in Aedes, or to the involvement of this region in the splicing mechanism underlying sex-specific regulation of this region (see below).

The predicted male-specific protein encoded by Aeadsx ${ }^{\mathrm{M} 1}$ is remarkably poorly conserved, displaying only very short stretches of similarity, as observed for Drosophila (Figure 3D) and others dipteran species (data not shown).

Finally, paralog search in the Aedes aegypti genome via the BLASTP matching function, using the three AeaDSX isoforms as virtual probes, revealed a single putative paralog gene (AAEL004696). However, this gene encodes a protein which shares with AeaDSX isoforms only a very well-conserved DM domain. This DM domain exhibits conservation of only one out of three DSX-DM domain-specific amino acids identified by Oliveira et al., [23].

\section{Phylogenetic relationship and molecular evolution of the Aedes aegypti dsx gene}

As remarked above, the dipteran DSX protein is essentially characterized by the two OD1 and OD2 domains, which constitute the most conserved portion of the $d s x$ gene across species. The high degree of conservation of these two domains is expected according with their regulative role in protein-protein and protein-DNA interactions.

To determine the phylogenetic position of AeaDSX ${ }^{\mathrm{F} 1}$, we defined a combined Aedes aegypti dsx nucleotide sequence, containing regions encoding respectively the non-sex-specific OD1 domain and the complete OD2 domain (non-sex-specific portion and the female-specific portion; nucleotides 94 to 288 joined with nucleotides 607 to 837 of GenBank DQ440532 CDS), and we aligned it with the corresponding homologous regions of $d s x$ sequences from fourteen other dipteran species: Drosophila melanogaster, Ceratitis capitata, Bactrocera tryoni, B. correcta, B. dorsalis, B. oleae, Anastrepha bistrigata, A. serpentina, A. amita, A. fraterculus, Anopheles gambiae, Musca domestica, Lucilia cuprina and Megaselia scalaris. Figure 4A shows the maximum parsimony and neighborjoining trees for this alignment. We used the lepidopteran Bombyx mori and Danaus plexippus $d s x$ sequences to root both trees. The resulting topologies agreed well with the taxonomy of the order Diptera and showed high confidence levels in the groups defined. As expected, based on phylogenetic relationships, both dendrograms for the combined $d s x$ nucleotide sequence grouped Aedes aegypti with Anopheles gambiae, and all the remaining dipteran species formed another group, while the lepidopteran Bombyx and Danaus representatives clustered in a basal clade.

Our analysis, performed with combined OD1/OD2 sequences, confirms the topologies obtained for insects $d s x$ genes by using the whole $\mathrm{DSX}^{\mathrm{F}}$ or DSX common portions encoding sequence $[36,37]$ the combined OD1/ non-sex-specific OD2 portion sequences [23].

We utilized the same dipteran $d s x$ OD1-OD2 combined nucleotide sequences to perform an analysis of the nucleotide variation across corresponding coding regions to examine whether the sequences evolve under purifying constraint or positive selection for amino acid changes. These analyses were conducted on the OD1 and OD2 coding sequences separately and on the OD2 coding sequence partitioned into the common region and the female-specific region (Figure 4B).

Even though diffuse purifying selection was detected in both OD1 and OD2 domains, the OD2 domain showed a relaxation of selective constraints compared to the OD1 domain. The difference between the $\mathrm{dN} / \mathrm{dS}$ values was due to the non-synonymous substitution rate, in particular in the female-specific region where $\mathrm{dN}$ was significantly higher than the $\mathrm{dN}$ values of the 


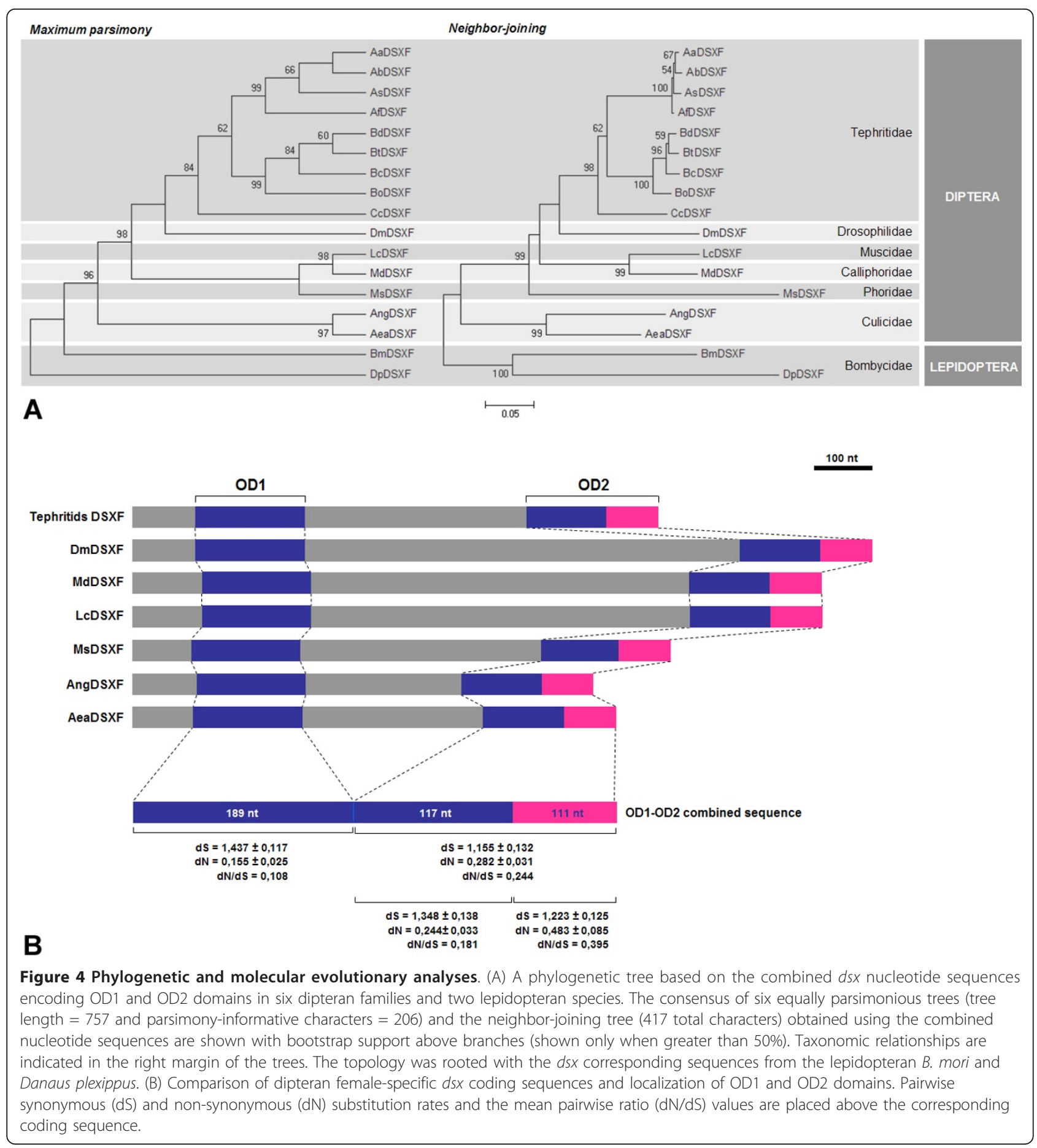

OD1 domain and the common part of OD2 domain. These findings suggest that OD1-OD2 domains of the $\mathrm{DSX}^{\mathrm{F}}$ protein have stringent structure/function relationships leading to a constrained evolution. However, the female-specific region of the OD2 domain exhibits a lower level of constraint. Amino acid changes in the female-specific portion of the DSX protein that affect dimerization dynamics might induce changes in the transcriptional regulation of $d s x$ target genes (possibly including heterochronic, heterotopic, heterometric or heterotypic variations, as well as recruitment/loss of specific target genes).

Hence, it is conceivable that even though DSX belongs to a highly conserved transcription factor protein family, 
it could be involved in the adaptive process and respond to the key force in insect evolution, sexual selection, by changing those protein regions involved in the control of expression of genes affecting dimorphic phenotypic traits in the two sexes.

\section{Developmental expression analysis of Aeadsx}

To analyze the developmental expression pattern of the Ae. aegypti $d s x$ gene, an RT-PCR analysis was performed on total RNA extracted from different stages of development using primer pairs spanning the Aeadsx sexspecifically regulated region. The recently isolated Aedes aegypti (Aearp49) homologue of the Drosophila rp 49 constitutively expressed gene was tested as the positive control for the RT-PCR analysis in non-saturating conditions [38-42]. Aearp49 was constitutively expressed from the embryonic stage of Aedes until adulthood, as in the fruitfly (Figure 5A).

In Drosophila, $d s x^{M}$ mRNAs are not readily detected in 3-10-hour-old embryos of either sex but are easily detected in 10-16-hour and 16-22-hour-old male XY embryos [43]. These authors showed that in male embryos, subsets of male somatic gonad cells were clearly stained with anti-DSX ${ }^{\mathrm{M}}$ during embryonic stage 13. In Anopheles gambiae, sex-specifically spliced $d s x$ mRNAs are detected in sexed adult mosquitoes, but no early developmental stages were investigated [19].

RT-PCR of Aedes with dsx $3 /$ dsx 5 primers amplified $0.5-\mathrm{kb}$ and $1.0-\mathrm{kb}$ cDNA products from very early embryonic stages (see Figure 5B.4) and an additional 1.5$\mathrm{kb}$ cDNA product from late larvae $\left(3^{\text {rd }}-4^{\text {th }}\right.$ instars). During pupal stages, the $1.5-\mathrm{kb}$ cDNA product was highly reduced, as well as the $1.0-\mathrm{kb}$ cDNA product (Figure 5B.1 and Figure 5A as control). At adult stages in sexed mosquitoes, the longer 1.0 - and 1.5-kb cDNAs were detected only in females, while the $0.5-\mathrm{kb}$ cDNA was detected only in males. Sequence analysis of the cDNA products showed that they were Aeadsx alternatively spliced transcripts encoding three different protein isoforms and corresponding in structure to those shown in Figure 1A. Sequence analysis of these cDNA products showed that exons $5 \mathrm{a}, 5 \mathrm{~b}$ and 6 are included in the same mRNA, which is detected in late larvae and at a lower level in pupae and in adult females. Transcripts including exons $5 \mathrm{~b}$ and 6 , but not exon $5 \mathrm{a}$, are detected from early embryonic stages during all development and in adult females. Transcripts including exon 6 (encoding the male-specific DSX C-terminus) but not exons 5a and 5b are detected from early embryonic stages throughout development and in adult males. Hence at least at adult stages, both $5 \mathrm{a}$ and $5 \mathrm{~b}$ exons are female specific, while exons 2, 3a, 3b, 4 and 6 are not sex-specific. Furthermore, it seems that exon $5 \mathrm{a}$ is used only from late larval stages, while exon $5 \mathrm{~b}$ is present already in early $d s x$ mRNA.
Although it is not presently possible to sex Aedes embryos or early larvae, the length correspondence of the adult sex-specific cDNA products with the respect to those detected at early stages of development suggests that the early sex-specific $d s x$ expression observed in Drosophila is conserved not only in the other dipteran species Ceratitis capitata [44] but also in the more distantly related Aedes aegypti.

In dissected ovaries, the dsx $3 / \mathrm{ds} \times 5$ primer pairs detected the three Aeadsx cDNA fragments amplified from late larval stages (Figure 5B.4). The shorter 0.5-kb cDNA product, which corresponded in adults to a malespecific mRNA, was surprisingly present in a femalespecific tissue, namely the ovaries. However, this cDNA product was absent in RT-PCR performed on the ovarydepleted female somatic carcasses (Figure 5B.4). The dissected females were young but not all were virgins. Furthermore, during the dissection of the ovaries, portions of the oviducts and uteri could have been included, leading to the possible presence of fertilized eggs in the dissected material. Because the dsx $3 /$ dsx 5 primer pair also detected the same $0.5-\mathrm{kb}$ cDNA product in $1.5 \mathrm{~h}$ embryos, it is possible that this product was absent in the ovaries but present in the fertilized eggs and hence not excluded in the final dissected samples.

We then used two other primer pairs to extend the RT-PCR expression analysis. The $\mathrm{ds} \times 3 / \mathrm{ds} \times 4$ pair led to amplification of the expected female-specific 0.4-kb long cDNA product in adult females (see Figure 5B.2). This cDNA product was amplified at larval and pupal stages, confirming the previous data that showed the presence of exon 5a during this developmental period. However, the 0.4-kb cDNA fragment was also amplified at embryonic and $1^{\text {st }} / 2^{\text {nd }}$ instar larval stages, indicating that exon $5 \mathrm{a}$ is present in mRNAs earlier than previously shown (see Figure 5B.2 and 5B.5). A possible explanation of this apparently contrasting data is that there is a third alternative mRNA in which exon $5 \mathrm{a}$ is present but exon $5 \mathrm{~b}$ and exon 6 are not. This mRNA could be generated by alternative polyadenylation at the 3' UTR of exon 5a. A northern blot analysis of total RNA from sexed adult mosquitoes showed the presence of a third female-specific Aeadsx transcript, offering support to this explanation (Figure $5 \mathrm{C}$ ). The two mRNAs including exon $5 \mathrm{a}$ are different in the 3' UTR but potentially encode the same $\mathrm{DSX}^{\mathrm{F} 1}$ protein. Furthermore, a putative polyadenylation signal (AATAGA) was identified in silico $333 \mathrm{bp}$ downstream of the stop codon present in exon 5a (Figure 6). Interestingly, the Apis mellifera $d s x$ homologue produces two female-specific transcripts using two alternative polyadenylation signals, and possibly as in Aedes, they both encode the same $\mathrm{DSX}^{\mathrm{F}}$ protein [21]. 
A

$\mathrm{E} \mathrm{L}_{12} \mathrm{~L}_{34} \mathrm{P} F \mathrm{M} \lambda$

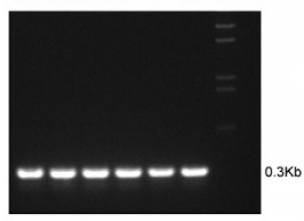

B
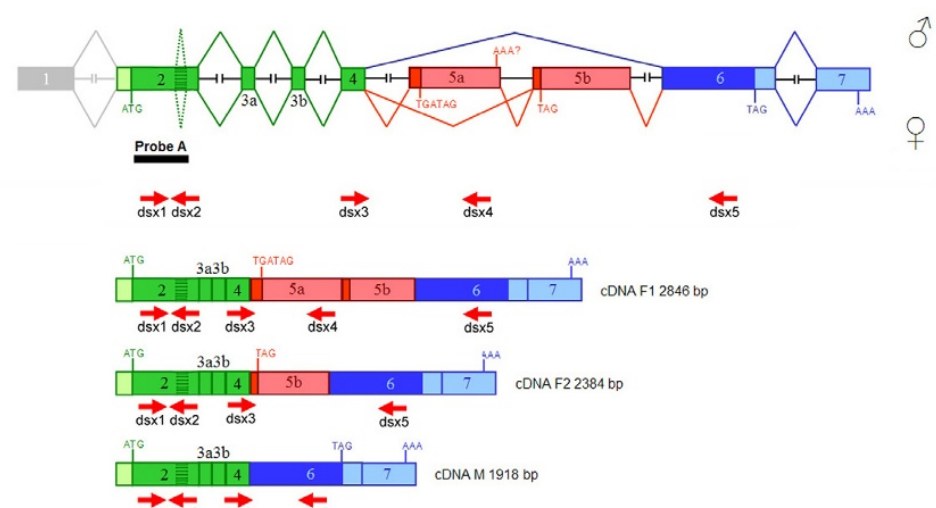

$\underset{\mathrm{ds} \times 1}{\overrightarrow{d s} \times 2} \quad \overrightarrow{d s \times 3} \quad \stackrel{d s \times 5}{-}$

$E L_{12} L_{34} P \quad F \quad M \quad \lambda$

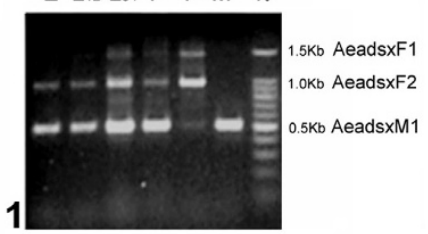

$d s \times 3 / d s \times 5$

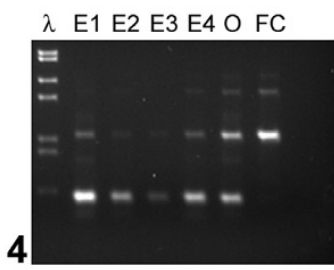

$\mathrm{ds} \times 3 / \mathrm{ds} \times 5$

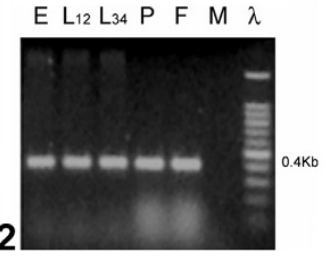

$\mathrm{ds} \times 3 / \mathrm{ds} \times 4$

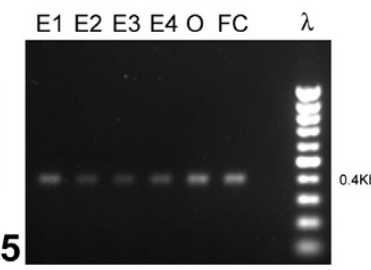

$\mathrm{ds} \times 3 / \mathrm{ds} \times 4$

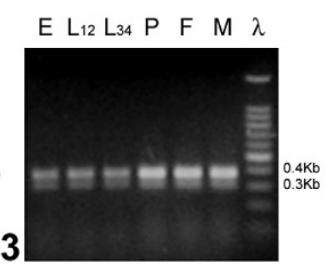

$\mathrm{ds} \times 1 / \mathrm{ds} \times 2$

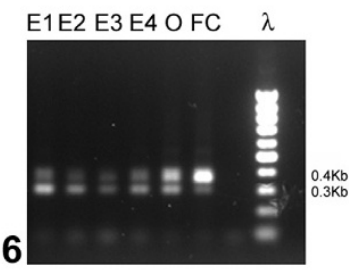

$d s \times 1 / d s \times 2$

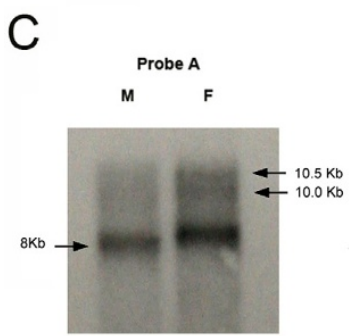

Figure 5 Developmental expression analyses of the Aeadsx gene. The analyses were performed on the following samples: $\mathrm{E} 1=0-1.5 \mathrm{~h}$ embryos; E2 = 1.5-2 h embryos; E3 = 2-5 h embryos; E4 = 8-12 h embryos; E: 0-36 h embryos; O = dissected ovaries; FC = female carcasses depleted of ovaries; $\mathrm{L}^{12}=$ early larvae; $\mathrm{L}^{34}=$ late larvae; $\mathrm{P}=$ pupae; $\mathrm{M}=$ adult males; $\mathrm{F}=$ adult female. Except for $\mathrm{M}, \mathrm{F}, \mathrm{O}$ and $\mathrm{FC}$ all samples are composed of mixed sexes. Negative controls are not shown. (A) Amplification of Ae. aegypti rp49 transcripts with the Aearp49+/Aearp49- primer pair. The Aedes aegypti ribosomal gene rp49 is constitutively expressed throughout development. (B) Aeadsx developmental expression pattern. 
(B.1 and B.4) The ds×3/ds×5 primer combination amplified at adult stages a 0.5-kb male-specific cDNA fragment and two female-specific cDNA fragments (1.0 kb and $1.5 \mathrm{~kb}$ ). These three bands were detected in pupae and late larvae, while the 1.5-kb band was absent in embryos and mid-larvae but present in ovaries and female carcasses. (B.2 and B.5) The ds×3-dsx4 primer combination amplified at adult stages a femalespecific CDNA fragment. A cDNA product of identical size was amplified at all developmental stages, including embryos, suggesting an early Aeadsx female-specific regulation. (B.3 and B.6) The dsx1/ds×2 primer combination amplified in all samples two slightly different cDNA fragments $(0.37 \mathrm{~kb}$ and $0.31 \mathrm{~kb})$, corresponding to the alternatively spliced isoforms of exon 2 either containing $(0.37 \mathrm{~kb})$ or not containing (0.31 kb) the $63-$ bp intronic sequence. In contrast to the data reported in Figure B.1-3, the RT-PCR results in Figure B.4, B.5 and B.6 lack of a positive semiquantitative control and the apparent changes in expression levels of Aeadsx isoforms during embryonic stages have to be further investigated. (C) A northern blot analysis was performed on total RNA $(20 \mu \mathrm{g})$ extracted from male and female Ae. aegypti adults. The genomic position of the utilized probe is indicated in Figure 5B. The observed molecular size of Aeadsx transcripts confirms that isolated Aeadsx CDNA clones were not full-length at the $3^{\prime}$ and $5^{\prime}$ ends.

$\mathrm{dsx} 1 / \mathrm{dsx} 2$ primers amplified in all samples two slightly different cDNA fragments $(0.37 \mathrm{~kb}$ and $0.31 \mathrm{~kb})$ corresponding to the alternatively spliced isoforms of exon 2 either containing or not containing the 63-bp intronic sequence (see Figures. 3A, 5B.3 and 5B.6). Interestingly, the relative ratio of the two RT-PCR products is dynamic during development, with the longer one becoming more prominent from pupal until adult stages (Figure 5B3 and Figure 5A as control). These data suggest that this Aeadsx intron-retention splicing event is subjected to stage-specific regulation. It would be of interest to check in future if also in Anopheles during development there is a similar $d s x$ expression pattern, concerning this small exon/intron.
Sex-specific expression of the Aeadsx gene was further confirmed by northern blot hybridizations. A probe of $500 \mathrm{bp}$ corresponding to the non-sex-specific region (Probe A) was hybridized on a northern blot of total RNA extracted from sexed adults. The probe identified three female-specific transcripts of $10.5 \mathrm{~kb}, 10.0 \mathrm{~kb}$ (weaker signals) and $8.5 \mathrm{~kb}$ (prominent signal) and an 8.0-kb male-specific transcript (Figure 5C).

\section{Putative splicing regulatory elements of Aeadsx gene}

In $D$. melanogaster, the female-specific splicing of $d s x$ pre-mRNA requires the binding of the splicing regulators TRA (which is female-specifically expressed) and TRA-2 (an auxiliary factor expressed in both sex) to six

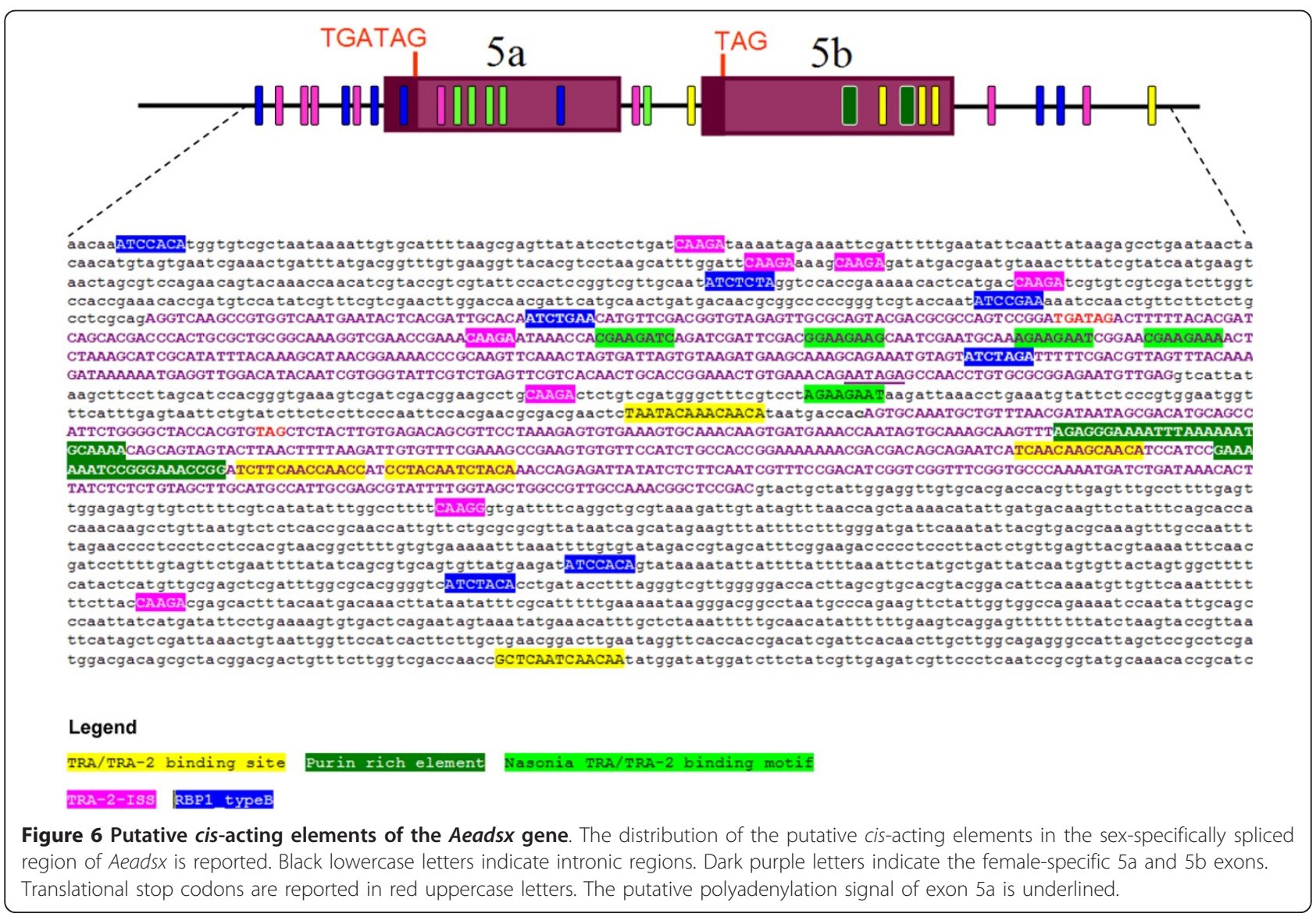


repeats of the dsxRE element and to one PRE (purine rich element) element, which is present only in the untranslated region of the $d s x$ female-specific exon (Figure 2). TRA and TRA-2 activate a weak (due to the presence of purine nucleotides in its polypyrimidine tract) 3' splicing acceptor site that precedes the femalespecific exon $[45,46]$. The activity of TRA/TRA-2 is not required for the processing of pre-mRNA in males, which constitutes the default type of splicing. This $d s x$ splicing regulation and the dsxRE element (13 nt long) are highly and widely conserved in many dipteran species (for review, see [3]).

Novel types of regulatory cis-elements have recently been identified in $d s x$ homologues of three non-dipteran species, such as the 20-bp CE1 element in the lepidopteran Bombyx mori dsx gene [47] and the 8-bp repeat in the tra/fem-regulated $d s x$ of Nasonia vitripennis and Apis mellifera [48]. These results revealed the potential evolvability of $d s x$ splicing paralleled by changes in the regulatory elements and the corresponding upstream splicing regulators. The CE1 element is indeed recognized by the PSI protein, which negatively regulates female-specific splicing in males [47]. The conserved 8-nt Nasonia/Apis repeat element [(T/G)GAAGAT(T/ A)] was suggested by Verhulst et al. (2010) to be a potential TRA/TRA-2 binding motif. However, there is no sequence similarity between this hymenopteran sequence and the 13-nt Drosophila TRA/TRA-2 binding element, known also as dsxRE [TC(T/A)(T/A)CAATCAACA], which is on the contrary conserved in all investigated dipteran species. This hymenopteran type of repeat element, which, in two distantly related hymenopteran species, appears to be conserved in sequence and clustered distribution, is likely a novel key regulatory element involved in the sex-specific splicing regulation of $d s x$. To avoid confusion, we referred to this novel element as $N v d s x$ RE (Nasonia vitripennis $d s x$ repeat element). NvdsxRE is also present in Nasonia tra [49] and fru [48], as well as, in Apis mellifera fem (not shown) $d s x$ and $f r u[48,50]$, strongly suggesting its involvement in sex-specific alternative splicing regulation. Hence, an upstream common splicing factor is expected to be present in hymenopterans, simultaneously controlling all three downstream target genes $(\mathrm{fem} / \mathrm{tra}, d s x$ and fru).

An in silico analysis of the intronic donor/acceptor splicing sequences of the Aedes $d s x$ gene was performed (Table 1) and revealed that almost all sequences have the conserved GT-AG motifs. Interestingly, in the splice-acceptor site preceding the female-specific exon $5 \mathrm{~b}$, the AG was substituted by GT, strongly indicating a significant deviation and hence a potentially regulated 3' splicing acceptor site. We thus defined more precisely the general consensus of the 3 ' acceptor splicing sites in the Aedes aegypti genome through the tabulation of 4688 random intron sequences extracted from the Ensembl database using the BIOMART tool. We derived a consensus number of $8.02 \pm 2.15$, a value equivalent to the one observed in the Anopheles genome based on 215 introns [19] (see Table 1). In the Aeadsx gene, pyrimidine stretches in most of the 3' splice sites do not deviate significantly from this consensus. However, the pyrimidine stretch preceding the female-specific exon $5 \mathrm{~b}$ deviates significantly from the consensus (5/12), suggesting that this sequence is a suboptimal 3' splicing acceptor site.

Analysis of the 5' splice donor sites of Aeadsx introns revealed that most of the sites are conserved in their consensus sequence (GTRAGY - Stephens et al. 1992). Indeed, the 5' splice donor site at the end of the femalespecific exon $5 \mathrm{~b}$ presents only three conserved positions out of six [51], suggesting again that this site could constitute a weak splice donor site requiring positive splicing regulation by an enhancer.

We then analyzed the Aeadsx genomic sequence, including the two female-specific exons $5 \mathrm{a}$ and $5 \mathrm{~b}$ and the surrounding intron regions, using the MACAW alignment software [52] to identify putative Drosophila, lepidopteran and hymenopteran cis-acting elements potentially involved in splicing regulation of Aeadsx. We utilized the Drosophila $d s x$ TRA/TRA-2 binding site and PRE element, the Bombyx CE1 element and $N v d s x$ RE element as virtual probes. We found the following:

1) Five copies of TRA/TRA-2 binding site sequences exclusively in the female-specific exon 5b. Interestingly, of the five repeats, three were located only $140 \mathrm{bp}$ and 1 repeat $1 \mathrm{~kb}$ away from the potentially regulated weak 5' splice donor site at the end of the female-specific exon $5 \mathrm{~b}$ (Figure 6). The fourth repeat was within the short intron 6 (208 bp), which separates the two female-specific exons, and the fifth repeat was located $1 \mathrm{~kb}$ downstream of the femalespecific exon $5 \mathrm{~b}$ in intron 7 (Figure 6). This is a strong indication of their potential involvement in the female-specific splicing of this Aeadsx region. The sequences of the five putative Aedes TRA/TRA2-binding sites are more similar to the Drosophila consensus than to the TRA/TRA-2 binding sites found in the Anopheles dsx homologue. The deviations in the sequences occur within the first four bases of the Aedes TRA/TRA-2-binding sites (See Additional file 4 - Table S2).

2) Two putative PRE elements exclusively in the female-specific exon $5 \mathrm{~b}$.

3) A cluster of four conserved $N v d s x$ REs exclusively in the female-specific exon $5 \mathrm{a}$ of the Aeadsx gene. The sequence conservation in an untranslated region 
Table 1 Exon-intron junctions of the Aeadsx gene

\begin{tabular}{|c|c|c|c|c|c|}
\hline \multicolumn{6}{|c|}{ Aeadsx gene } \\
\hline Exon No. & Exon size (bp) & Splice-donor & Intron size (bp) & Splice-acceptor & $\mathrm{N}^{\circ}$ of $\mathrm{Y}$ \\
\hline 1 ? & - & - & - & - & \\
\hline \multirow[t]{2}{*}{2} & 518 & A G & 274879 & $\mathrm{~N} \mathrm{H}$ & 12 \\
\hline & & TTGCAG/gtaggtgtgaggcata & & tctcctctcttttcag/GCAACC & \\
\hline \multirow[t]{2}{*}{$3 a$} & 45 & P V & 43797 & GP & 10 \\
\hline & & TACCAG/gtgagttcgctgttga & & tctcttctggtttcag/TTGGCC & \\
\hline \multirow[t]{2}{*}{$3 b$} & 48 & T D & 85670 & $\mathrm{DE}$ & 9 \\
\hline & & GAACAG/gtgcgtacttccttaa & & tcgtttccaatttcag/ACGACG & \\
\hline \multirow[t]{2}{*}{4} & 135 & $\mathrm{E} G$ & 13860 & $Q A$ & 11 \\
\hline & & ACGAAG/gtatgggggttcttac & & cttctctgcctcgcag/GTCAAG & \\
\hline \multirow[t]{2}{*}{$5 a$} & 461 & n.c. & 208 & Q M & 5 \\
\hline & & gttgag/gtcattataagcttcc & & acataatgaccacagt/GCAAAT & \\
\hline \multirow[t]{2}{*}{$5 b$} & 465 & $\mathrm{n} \cdot \mathrm{c}$. & 10392 & Y D & 8 \\
\hline & & cgacag/gtactgctattggagg & & tcaatccctcaaacag/GATACG & \\
\hline 6 & 1063 & $\begin{array}{l}\text { n.c. } \\
\text { acgaag/gtgagtgttctttttt }\end{array}$ & 22437 & $\begin{array}{r}\text { n.c. } \\
\text { ctcttttcttcaacag/tttcac }\end{array}$ & 11 \\
\hline 7 & 449 & $\begin{array}{l}\text { n.c. } \\
\text { tacacacgtacacattaaaatag }\end{array}$ & - & - & - \\
\hline \multicolumn{2}{|c|}{ Consensus } & $\begin{array}{l}\text { AG/gtRagt } \\
\mathrm{C}\end{array}$ & & YYYYYYYYYYYYNYag/G & $8,02+/-2,15$ \\
\hline
\end{tabular}

The exon/intron/exon boundaries of Aeadsx gene are reported. Exonic coding sequences are shown in uppercase letters, and non-coding regions (n.c.) are in lowercase letters. Encoded aminoacids are reported above the first base of each triplet. $\mathrm{R}=\mathrm{A}$ or $\mathrm{G}$ nucleotide. $\mathrm{Y}=\mathrm{T}$ or $\mathrm{C}$ or nucleotide. $\mathrm{N}=$ any nucleotide. The number of pyrimidines $(\mathrm{Y})$ in the $12 \mathrm{bp}$ preceding the $3^{\prime}$ splice-acceptor site (NYag) is indicated. The consensus number of pyrimidines (8.02) was derived from the analysis of $4688 \mathrm{Ae}$. aegypti splice-acceptor sites. The Aeadsx gene intron 5 (13,860 bp) represents the intron preceding the female-specific exon $5 \mathrm{a}$, and its polypyrimidine stretch does not deviate significantly from the consensus. The splice-acceptor site of the short 208-bp intron preceding the female-specific exon $5 b$ is a weak acceptor site, as is the female-specific exon $5 b$ splice-donor site, which deviates significantly from the consensus sequence.

and its clustering within the regulated genomic region strongly suggest a functional relevance of this element. A further copy of the $N v d s x \mathrm{RE}$ repeat is located in the 208-bp intron between Aeadsx female-specific exons $5 \mathrm{a}$ and $5 \mathrm{~b}$. A similar search for NvdsxREs was also performed for the Anopheles and Drosophila $d s x$ and fru homologues but failed to identify any putative conserved element.

We extended our analysis to look for the presence of two more cis-acting elements in the Aeadsx gene, the RBP1 binding site and the TRA-2-ISS element. In Drosophila, RBP1, a non-sex-specific SR splicing factor, contributes to the activation of female-specific $d s x$ splicing in vivo by recognizing two RBP1 target sequences (Type A: DCADCTTTA; Type B: ATCYNNA, [53]) within the purine-rich polypyrimidine tract of the weak female-specific 3' splice site [54]. Furthermore, the expression of functional TRA-2 protein in the male germline of Drosophila is regulated through a negative feedback mechanism, which is evolutionarily conserved in many Drosophila species, in which a specific TRA-2 isoform represses splicing of the M1 intron in the TRA2 pre-mRNA by binding to an intronic splicing silencer
(CAAGR; TRA-2-ISS). Interestingly, the search in Aeadsx for putative RBP1 and TRA-2-ISS binding elements was successful, revealing their presence as a main cluster in the intronic region upstream of the femalespecific exon 5a (Figure 6).

The presence of all these conserved regulatory elements suggests that TRA-like, TRA-2 and RBP1 conserved proteins could be involved in Ae. aegypti as upstream $d s x$ splicing regulators, as in Drosophila. As previously reported for Anopheles gambiae [55], tra-2 and $r b p 1$ putative orthologs are also present in the Aedes genome. We failed to find clear BLAST hits for TRA homologous proteins in Aedes or Anopheles, probably because of the very weak sequence conservation of TRA, which has been well documented in dipteran species and in Hymenopterans [9,13,14,49,56,57].

In Table S2 of additional file 4, the sequences of all identified Aedes aegypti dsx repeat elements and their counterparts in Drosophila, Anopheles and Nasonia are summarized.

\section{Evolution of splicing regulation in Aeadsx}

Our analysis revealed that a bipartite distribution of putative cis-acting elements is present between the two 
female-specific Aeadsx exons, with TRA-2-ISS, RBP1 binding sites and $N v d s \times \mathrm{RE}$ almost exclusively present in the "strong" exon 5a and in the upstream intron, and putative Aedes TRA/TRA-2 binding sites and the PRE element present only in the "weak" exon $5 \mathrm{~b}$. The analysis of acceptor and donor splicing sites of the Aeadsx sex-specific region revealed that $3^{\prime}$ and 5' splicing sites flanking exon 5a ("strong") are apparently optimal, while 3 ' and 5' splicing sites flanking exon 5b ("weak") strongly deviate from consensus. These findings suggest that in Aedes aegypti, the regulation of the sex-specific splicing of $d s x$ is achieved by a different mechanism than in Drosophila and other dipteran species, using at least two different splicing regulators acting on the two alternatively used female-specific exons.

Our study show that splicing regulation of $d s x$ is not as robustly conserved as previously described in other dipteran species, that that there is a bipartite distribution of putative cis-regulatory elements in the female-specific exons of Aeadsx, and that some of these putative cis elements are also present in the $d s x$ of hymenopteran species. Based on our study we propose that the upstream splicing regulators of Aeadsx splicing act in females as activators of the weak female-specific exon $5 \mathrm{~b}$, while simultaneously repressing the utilization of the first female-specific exon $5 \mathrm{a}$ in a subset of Aeadsx pre-mRNAs. In the other Aeadsx mRNAs female-specific exon $5 \mathrm{a}$ is also included in the mature transcript, because this repression does not take place constitutively or very efficiently. We propose that in males, both exons $5 \mathrm{a}$ and $5 \mathrm{~b}$ are skipped out of the mRNA by splicing factors able to inhibit the use of the corresponding strong splice site in exon $5 \mathrm{a}$.

We propose a model of Aeadsx regulation in which, similarly to Drosophila and other dipteran species, the use of the conserved female-specific exon $5 b$ is enhanced in females by a splicing activator, while a splicing repressor acts on exon $5 \mathrm{a}$. A female-specific SR-F protein (a TRA-like protein) would be required in females to promote the alternative inclusion of female-specific exon $5 \mathrm{~b}$ through the TRA/TRA-2 elements, while "the strong" exon $5 \mathrm{a}$ would be included by default; a male-specific SR-M would be required in males to repress the inclusion of the "strong" exon $5 \mathrm{a}$ possibly by TRA-2-ISS elements and $N v d s x$ RE, while exon $5 \mathrm{~b}$ would be excluded because of the absence of the SR-F protein, leading to the $d s x$ male-specific splicing. The splicing repression of exon 5 a could be achieved by a direct action of the male-determining gene, which would encode a splicing factor in this case.

We suggest that the peculiar evolvability of $d s x$ splicing regulation in Aedes could be an indication that, differently to other dipteran species, the primary signal $M$ acts directly on $d s x$ in this mosquito species, which have homomorphic sexual chromosomes and hence a "young" recently recruited Y chromosome bearing the M. The presence of multiple copies of the Drosophila TRA/TRA-2 binding element and the TRA-2-ISS element in exon $5 \mathrm{a}$ and its upstream intron sequence suggests an involvement of a putative Aedes TRA-2 as a cofactor of SR splicing regulators (possibly including the male-determining factor) in the regulation of $d s x$ splicing. In the Aedes aegypti genome, there are three putative tra-2 orthologs that could be involved in this process, either alone or in combination.

Less clear is the reason for the presence of the $N v d s \times \mathrm{RE}$ element. These elements are completely different from the Drosophila consensus and hence are not expected to be targets of TRA/TRA-2 orthologous proteins but rather of other splicing factors. Perhaps these are additional splicing signals required to evolutionarily stabilize the $d s x$ sex-specific splicing, which appears to be absent in Drosophila and Anopheles dsx female-specific exons.

We propose a model for sex determination in Aedes aegypti in which the male-determining factor $\mathrm{M}$ acts directly or indirectly either to activate a downstream SR-M factor or to encode the SR-M itself or finally to inhibit an SR-F factor. Two alternative parallel regulatory events in both sexes lead alternatively to the Aeadsx male-specific or female-specific splicing (Figure 7).

In Apis mellifera, Cristino et al. [22] reported that honeybee $d s x$ is sex-specifically spliced, indicating that the use of different splicing forms of DSX in controlling sexual differentiation was present in the common ancestor of holometabolous insects. In Apis sex-specific splicing regulation shares similar features of both $B$. mori splicing regulation (female-specific exon skipping) and Drosophila splicing regulation (sex-specific 3' splice site). Based on a further Apis $d s x$ study Cho et al. [21] proposed that the female $d s x$ form is the default (as observed in the silk moth Bombyx $d s x$ ) in ancestral holometabolous insects and that the male form is generated by suppressing the female-specific splicing. On the basis of the parsimony principle, they inferred from the above observations the following: (1) the common ancestor of holometabolous insects had both the dipteran-type and lepidopteran-type sex-specific $d s x$ splicing patterns, (2) hymenopterans retain both ancestral patterns, and (3) dipterans and lepidopterans each retain either one or the other of the ancestral patterns.

The Aedes $d s x$ gene contains not only the Drosophila TRA/TRA-2 repeats but also hymenopteran-like $d s x$ RE repeats and seems to have a female-specific default splicing. This is similar to the regulation of Apis $d s x$ gene but different from other dipteran species including the other mosquito Anopheles gambiae. Hence, the ancestral $d s x$ splicing regulation observed in Apis (and in lepidopteran) seems to have been stably maintained in Aedes 


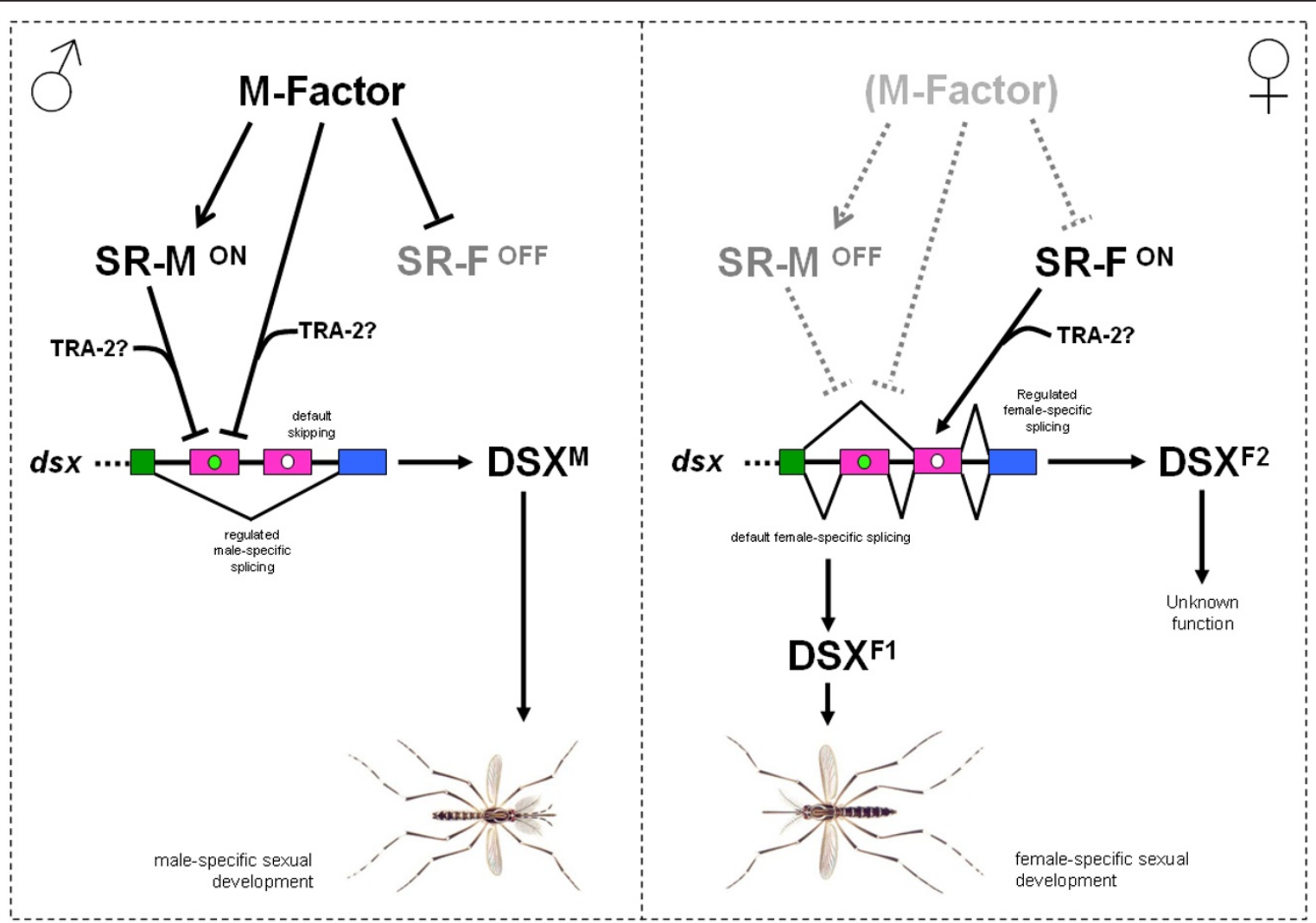

Figure 7 Model for sex determination in Aedes aegypti. In male embryos a male-determining factor (M) inhibits the function of an SR-F protein required for the female-specific splicing of exon $5 b$ and activates the function of an SR-M protein required for the male-specific repression of exon $5 \mathrm{a}$. It is also conceivable that the $M$ could directly control the splicing of Aeadsx exon $5 \mathrm{a}$. In any case, the result is the skipping of both female-specific exons and only a male-specific product of $d s x$ gene is produced in male embryos and this product induces the male development. In female embryos the absence of the $M$ leads to the default splicing of female-specific exons $5 a$ and $5 b$ and to the activation of the SR-F factor which in turn regulates the female-specific splicing of exon $5 \mathrm{~b}$. As a result two female-specific DSX proteins are produced that induce female development. Alternative male-specific and female-specific exons are represented as blue boxes and pink boxes, respectively. Green dot represent NvdsxRE and TRA-2-ISS elements. White dot represents TRA/TRA-2 binding sites.

aegypti, which constitutes the first dipteran species reported with this type of splicing regulation.

\section{Conclusion}

As in other dipteran species, $d s x$ seems to be involved in the control of sexual differentiation in Aedes mosquito based on its conservation of sex-specific expression. In contrast to other dipteran orthologs, the Aeadsx gene produces a novel female-specific isoform of DM-domain containing transcription factor differing in the C-terminus. The novel female-specific isoform has the long common region (248 aa) present in the other two sex-specific isoforms and a short different C-terminus (18 aa). Aeadsx gene exhibits more complex sex-specific splicing regulation (an exon skipping in males, exon skipping in females, intron retention in both sexes and two potential alternative polyadenylation sites) that seems to be a combination of dipteran and hymenopteran types of $d s x$ regulation.

Our study show that 1 ) $d s x$ splicing regulation is slightly less conserved then previously described in dipteran species, including the other mosquito Anopheles gambiae, 2) there is a bipartite distribution of putative cis regulatory elements in the two alternatively regulated female-specific Aeadsx exons, 3) the putative cis elements described in the $d s x$ of dipteran and hymenopteran species are present also in untranslated regions of the Aedes dsx gene.

These findings led us to propose that the upstream splicing regulators of $d s x$ splicing seem to act $\mathrm{A}$ ) in females as activators of the weak female-specific exon $5 \mathrm{~b}$, which simultaneously causes the skipping of the first female-specific strong exon $5 \mathrm{a}$ in a subset of Aeadsx pre-mRNA. In the remaining Aeadsx pre-mRNA molecules a default splicing event include the strong femalespecific exon $5 \mathrm{a}$ in the mature transcript; $\mathrm{B}$ ) in males as repressors of the female-specific strong exon $5 \mathrm{a}$, where the weak female-specific exon $5 b$ is spliced out by a default mechanism.

The evolution of these differences in the splicing regulation of the $d s x$ orthologs of two mosquitoes, Anopheles 
and Aedes, could be explained by a direct involvement of different primary signals that evolved upstream of $d s x$, namely the Y-linked $M$ factor in Anopheles and the $\mathrm{M} / \mathrm{m}$ male-determining locus on one (neo Y) of the Aedes sexual homomorphic chromosomes, overcoming the use of an intermediate "transducer" such as transformer, although widely conserved in insects [58].

The identification of female- and male-specific transcripts of Aeadsx represents an important step toward the understanding of the sex differentiation process in Ae. aegypti. This genomic analysis and the identification of novel putative cis-acting elements will facilitate the isolation of upstream regulators, which are still unidentified despite a sequenced genome, also for Anopheles $d s x$ orthologue. Recently, transcription profiles of adult female and male Aedes mosquitoes were defined through microarray analysis, leading to the identification of 669 and 635 transcripts enriched in females and males, respectively [26]. The differential expression of hundreds of these genes, which could be involved in controlling the phenotypic and molecular sexual dimorphisms of Aedes aegypti, could be directly achieved by AeaDSX isoforms. In future, in vivo knockdown experiments by RNAi against the three sex-specific Aedes DSX isoforms will confirm this hypothesis and will led to the identification of new DSX targets in insects.

Furthermore, this knowledge may result in the development of novel approaches for vector-targeted control of disease, as recently shown by the isolation and use of sex-specifically expressed genes to develop transgenic sexing strains in Aedes aegypti, which are useful for the male sterile insect technique [59].

\section{Methods}

\section{Aeadsx cloning strategy}

Our starting point was the genome sequence of Ae. aegypti AaegL1 [26]. We performed a BLASTP search of the Ensembl Ae. aegypti genomic database (http://www. ensembl.org/) using the non-sex-specific region of Anopheles gambiae DSX protein (236 aa) as a virtual probe, and we identified a draft sequence located in supercontig 1.370 encoding a putative protein region $68 \%$ identical to the corresponding region encoded by An. gambiae $d s x$ (Angdsx). In Angdsx, sex-specific transcripts share the same 3' UTR sequence [19]. This is in contrast to Drosophila, in which $d s x$ sex-specific transcripts terminate with different 3' UTR sequences [5,7]. Assuming that the Aeadsx homologue shares the same 3' UTR regulation of An. gambiae, we used a male-specific nucleotide sequence derived from an $A n g d s x$ cDNA clone (Angds $x^{M}$, kindly provided by Pannuti A. and Lucchesi J., Emory University - USA) to search via the BLASTN matching function of an Ae. aegypti EST database (http://aaegypti.vectorbase.org/). We identified a cDNA sequence (NABNG41TR, brugia_4289 of 537 bp) showing 59\% identity at the nucleotide level (166/282). Using specific primer pairs for this EST clone (dsx 5 primer) and for the genomic sequence previously identified in silico encoding the $\mathrm{N}$-terminal region of the putative Aedes DSX protein (dsx1 primer), we performed an RT-PCR analysis on RNA samples extracted from adult sexed $A e$. aegypti mosquitoes and successfully amplified sex-specific products of the Aeadsx gene (two female-specific and one male-specific cDNAs).

\section{RT-PCR analyses}

Total RNA was extracted using the TRIzol Reagent (Invitrogen) from the following developmental stages: $\mathrm{E} 1=0-1.5$ $\mathrm{h}$ embryos; E2 $=1.5-2 \mathrm{~h}$ embryos; E3 $=2-5 \mathrm{~h}$ embryos; E4 = 8-12 h embryos; $\mathrm{E}=0-36 \mathrm{~h}$ embryos; $\mathrm{O}=$ dissected ovaries; $\mathrm{FC}=$ female carcasses depleted of ovaries; $\mathrm{L}^{12}=$ early larvae; $\mathrm{L}^{34}=$ late larvae; $\mathrm{P}=$ pupae; $\mathrm{M}=$ adult males; $\mathrm{F}=$ adult female. All samples except for M, F, O and FC are constituted by mixed sexes. Aliquots of $1 \mu \mathrm{g}$ of each RNA were treated with RNase-free DNase I, Amplification Grade (Invitrogen), and first-strand cDNAs were synthesized by Superscript First-Strand Synthesis System (Invitrogen) according to the manufacturer's instruction. One twentieth of the cDNA template was used in $49-\mu$ l PCRs containing primer pairs specific for the various cDNAs, $50 \mathrm{mM} \mathrm{KCl}$, $10 \mathrm{mM}$ Tris $\mathrm{HCl}$ (pH 8.3), $1.5 \mathrm{mM} \mathrm{MgCl}, 1 \mu \mathrm{M}$ each primer, $200 \mu \mathrm{M}$ dNTPs (Roche), and 2.5 units Taq DNA polymerase (Roche). Appropriate annealing temperatures and cycle numbers were adjusted to individual primers. Positive controls and standardization were performed with the following primers:

Aearp49+ (5'-CCAAGATCGTCAAGAAGCGG-3')

Aearp49- (5'-GGTTGGTCACAGCGATGG-3').

These primers amplify the constitutive ribosomal protein 49 of Aedes aegypti. Amplifications were performed by stopping the PCR reaction after 25 cycles, 30 cycles, 35 cycles and 40 cycles. The amplification products were analyzed on $1 \%$ agarose gels. Following 30 cycles of RT-PCR amplification, we observed no saturation in the intensity of the Aearp49 amplification fragment.

Other Aeadsx-specific primers included:

dsx1: 5'-GAACGCCGCCGAACTGTG-3'

dsx2: 5'-ATCTTCGGTGCTGGGACAG-3'

dsx3: 5'-GATACTGAAAGGCGCCGACG-3'

dsx4: 5'-ATTGTGTGTCCAACCTCATTTC-3'

dsx5: 5'-GCAGAATATGGGACTGGTGC-3'.

The amplification products were cloned into the pGEMT-Easy Vector (Promega) according to manufacturer's instructions.

\section{Rapid amplification of CDNA ends (RACE) and sequence analyses}

The 5'- and 3 '-ends of the Aeadsx cDNAs were determined with the Smart Race Amplification kit (Clontech 
Laboratories). Reverse transcription was performed as recommended by the supplier. cDNAs containing open reading frames (ORFs) were cloned into the pGEMT-Easy Vector (Promega) and sequenced with the Applied Biosystem BigDye 1.1 sequencing kit. Sequence alignments were performed with the Clustal-W software. The following Ae. aegypti cDNA sequence files were deposited in GenBank: Aeadsx $^{\mathrm{M} 1}$ [GenBank: DQ440534], Aeadsx ${ }^{\mathrm{F} 1}$ [GenBank: DQ440532] and Aeadsx ${ }^{\mathrm{F} 2}$ [GenBank: DQ440533].

\section{Northern blot analysis}

Twenty micrograms of total RNA from adult sexed mosquitoes was isolated as described above and blotted onto nylon membranes (Hybond NX - Amersham Pharmacia). Hybridizations were performed at $42^{\circ} \mathrm{C}$ overnight in a buffer of $50 \%$ formamide, $6 \times$ SSC, $5 \times$ Denhardt, 1\% SDS and $100 \mu \mathrm{g} / \mathrm{ml}$ salmon sperm DNA. Following hybridizations, the filters were washed for 10 minutes at room temperature in $2 \times$ SSC and $0.1 \%$ SDS, followed by two washes for 20 minutes each at $42^{\circ} \mathrm{C}$ in $1 \times$ SSC and $0.1 \%$ SDS, and finally one wash for $15 \mathrm{~min}-$ utes at room temperature in $1 \times$ SSC and $0.1 \%$ SDS. The female-specific probe (400 bp) was prepared by nicktranslation (Invitrogen) labeling of Aeadsx cDNA sequences in the presence of $\left[\alpha-{ }^{32} \mathrm{P}\right] \mathrm{dCTP}(3,000 \mathrm{Ci} /$ mmol Amersham). Filters were exposed on Kodak $\mathrm{X}$-OMAT Scientific imaging film.

\section{Phylogenetic and Molecular Evolutionary Analyses}

The nucleotide sequences encoding the OD1 domain and the OD2 domain of the following dipteran doublesex homologues (Drosophila melanogaster [GenBank: ABK30895], Ceratitis capitata [GenBank: AAN63598], Bactrocera tryoni [GenBank: AAB99947], B. correcta [GenBank: ACN73403], B. dorsalis [GenBank: AAV85891], B. oleae [GenBank: CAD67986], Anastrepha bistrigata [GenBank: ABF50960], A. serpentina [GenBank: ABF50957], A. amita [GenBank: ABF50961], A. fraterculus [GenBank: ABF50955], Anopheles gambiae [GenBank: AAZ78363], Aedes aegypti [GenBank: ABD96571], Musca domestica [GenBank: AAR23812], Lucilia cuprina [GenBank: ADG37649] and Megaselia scalaris [GenBank: AAK38831]) were aligned using Clustal-W, and the resulting alignment [60] was manually edited using BioEdit v7.0.5.3. The maximum parsimony and neighborjoining trees were obtained using the MEGA 5 package [61]. The reliability of the resulting topologies was tested by the bootstrap method [62]. Bootstrap proportions were calculated by analysis of 1500 replicates. Phylogenies were rooted using $d s x$ OD1 and OD2 domains of Lepidoptera Bombyx mori [GenBank: NM_001043406] and Danaus plexippus [GenBank: EY269445]. Pairwise synonymous (dS) and non-synonymous $(\mathrm{dN})$ nucleotide substitution rates were estimated using the Jukes-Cantor distance model with the Nei-Gojobori method [63] implemented in MEGA 5.
The mean pairwise ratio of $\mathrm{dN} / \mathrm{dS}$ was calculated and used to examine whether the sequences evolve under purifying constraint $(\mathrm{dN} / \mathrm{dS}<1)$ or positive selection for amino acid changes $(\mathrm{dN} / \mathrm{dS}>1)$.

\section{Additional material}

\begin{abstract}
Additional file 1: Table S1 Modified Censor output table of repetitive elements identified in Aeadsx intronic regions.

Additional file 2: Figure S1 Censor analysis on Aeadsx introns. Censor software graphically maps detected repeats with color-coding of different types of repeats. Legend of Censor output is available at: http:// www.girinst.org/censor/help.html\#MAP.

Additional file 3: Figure S3 Microsynteny analysis. Syntenic $d s x-$ containing regions of Aedes aegypti and Anopheles gambiae are reported. In red the position of putative genes.

Additional file 4: Tables S2 Putative cis-acting elements identified in Aeadsx and homologous elements in D. melanogaster, An. gambiae and $\boldsymbol{N}$. vitripennis. Bold letters indicate identical positions respect to the sequences of Drosophila or Nasonia elements.
\end{abstract}

\section{Acknowledgements}

We are deeply grateful to Serena Aceto (Dept. Biol. Sciences, Federico II, Naples, Italy) for helpful suggestions on sequence data analysis and phylogenetic and molecular evolutionary analyses. We thank Paola Santoro (National Institute of Statistic - ISTAT, Rome, Italy) for the useful suggestions on statistical data analysis. We thank Maria Sica (Dept. Biol. Sciences, Federico II, Naples, Italy) for her technical assistance. GS greatly thanks Kitsos Louis (IMBB, Crete, Greece), who suggested and encouraged him to start a sex determination Aedes aegypti project; GS thanks Gustavo Kourì, Juan Bisset and all the colleagues of the IPK (Habana, Cuba), especially Daniel Limonta and Clara Elena Delgado for hosting the visiting GS, MS and UM and for fruitful discussion on Aedes aegypti dsx data. This work was funded by WHO Grant A30289 (2004-2006) to GS.

\section{Author details}

${ }^{1}$ Department of Biological Sciences - Section of Genetics and Molecular Biology. University of Naples "Federico II" - Italy. ${ }^{2}$ CDF - Centro Diagnostico Flegreo, Naples - Italy. ${ }^{3}$ Department of Public Health - Parasitology Section. University of Rome "La Sapienza" - Italy. "Department of Structural and Functional Biology. University of Naples "Federico II" - Italy. "Institute of Genetics and Biophysics "Adriano Buzzati-Traverso" CNR Naples - Italy.

\section{Authors' contributions}

GS designed the general research project. GS, BA, CP, FL, MS and UM designed the experimental plans. UM performed the molecular cloning experiments. UM, MS and FL performed the $d s x$ developmental expression analyses, and MS performed the Aearp49 developmental expression analysis. UM and MS performed in silico analyses to define the $d s x$ genomic organization. AM and VZ helped with the molecular biology experiments. MS and GS planned comparative analyses to identify cis-regulatory elements potentially involved in the $d s x$ splicing regulation. MS performed bioinformatic, phylogenetic and molecular evolutionary analyses. UM, MS, AM, VZ, FL, BA, CP and GS analyzed and discussed data. MS and GS wrote the paper. All authors read and approved the final manuscript.

Received: 31 July 2010 Accepted: 10 February 2011 Published: 10 February 2011

\section{References}

1. Raymond SC, Shamu EC, Shen MM, Seifert JK, Hirsch B, et al: Evidence for evolutionary conservation of sex-determining genes. Nature 1998, 391(6668):691-695.

2. Zarkower D: Invertebrates may not be so different after all. Novartis Found Symp 2002, 244:115-126, discussion 126-135, 203-116, 253-117. 
3. Sanchez L: Sex-determining mechanisms in insects. Int J Dev Biol 2008, 52(7):837-856

4. An W, Cho S, Ishii H, Wensink CP: Sex-specific and non-sex-specific oligomerization domains in both of the doublesex transcription factors from Drosophila melanogaster. Mol Cell Biol 1996, 16(6):3106-3111.

5. Baker SB, Wolfner FM: A molecular analysis of doublesex, a bifunctional gene that controls both male and female sexual differentiation in Drosophila melanogaster. Genes Dev 1988, 2(4):477-489.

6. Baker SB, Belote MJ: Sex determination and dosage compensation in Drosophila melanogaster. Annu Rev Genet 1983, 17:345-393.

7. Burtis CK, Baker SB: Drosophila doublesex gene controls somatic sexual differentiation by producing alternatively spliced mRNAs encoding related sex-specific polypeptides. Cell 1989, 56(6):997-1010.

8. Salvemini M, Robertson M, Aronson B, Atkinson P, Polito CL, et al: Ceratitis capitata transformer-2 gene is required to establish and maintain the autoregulation of Cctra, the master gene for female sex determination. Int J Dev Biol 2009, 53(1):109-120.

9. Pane A, Salvemini M, Bovi PD, Polito C, Saccone G: The transformer gene in Ceratitis capitata provides a genetic basis for selecting and remembering the sexual fate. Development 2002, 129(15):3715-3725.

10. Ruiz FM, Sanchez L: Effect of the gene transformer of Anastrepha on the somatic sexual development of Drosophila. Int I Dev Biol 2010, 54(4):627-633.

11. Sarno F, Ruiz FM, Eirin-Lopez MJ, Perondini LA, Selivon D, et al: The gene transformer-2 of Anastrepha fruit flies (Diptera, Tephritidae) and its evolution in insects. BMC Evol Biol 2010, 10:140.

12. Burghardt G, Hediger M, Siegenthaler C, Moser M, Dubendorfer A, et al: The transformer2 gene in Musca domestica is required for selecting and maintaining the female pathway of development. Dev Genes Evol 2005, 215(4):165-176.

13. Hediger M, Henggeler C, Meier N, Perez R, Saccone G, et al: Molecular characterization of the key switch $f$ provides a basis for understanding the rapid divergence of the sex-determining pathway in the housefly. Genetics 2010, 184(1):155-170.

14. Concha C, Scott JM: Sexual development in Lucilia cuprina (Diptera, Calliphoridae) is controlled by the transformer gene. Genetics 2009, 182(3):785-798.

15. Hediger M, Burghardt G, Siegenthaler C, Buser N, Hilfiker-Kleiner D, et al: Sex determination in Drosophila melanogaster and Musca domestica converges at the level of the terminal regulator doublesex. Dev Genes Evol 2004, 214(1):29-42.

16. Saccone G, Salvemini M, Pane A, Polito CL: Masculinization of XX Drosophila transgenic flies expressing the Ceratitis capitata DoublesexM isoform. Int J Dev Biol 2008, 52(8):1051-1057.

17. Alvarez M, Ruiz FM, Sanchez L: Effect of the gene doublesex of anastrepha on the somatic sexual development of Drosophila. PLoS One 2009, 4(4):e5141.

18. Pannuti A, Kokacitak T, Lucchesi CJ: Drosophila as a Model for the study of Sex Determination in Anopheline and aedine Mosquitoes. In AreaWide Control of Fruit Flies and Other Insect Pests. Edited by: Tan HK. Penang: Penerbit Universiti Sains; 2000.

19. Scali C, Catteruccia F, Li Q, Crisanti A: Identification of sex-specific transcripts of the Anopheles gambiae doublesex gene. J Exp Biol 2005, 208(Pt 19):3701-3709.

20. Ohbayashi F, Suzuki GM, Mita K, Okano K, Shimada T: A homologue of the Drosophila doublesex gene is transcribed into sex-specific mRNA isoforms in the silkworm, Bombyx mori. Comp Biochem Physiol B Biochem Mol Biol 2001, 128(1):145-158.

21. Cho S, Huang YZ, Zhang J: Sex-specific splicing of the honeybee doublesex gene reveals 300 million years of evolution at the bottom of the insect sex-determination pathway. Genetics 2007, 177(3):1733-1741.

22. Cristino SA, Nascimento MA, Lda CF, Simoes LZ: A comparative analysis of highly conserved sex-determining genes between Apis mellifera and Drosophila melanogaster. Genet Mol Res 2006, 5(1):154-168.

23. Oliveira CD, Werren HJ, Verhulst CE, Giebel DJ, Kamping A, et al: Identification and characterization of the doublesex gene of Nasonia. Insect Mol Biol 2009, 18(3):315-324.

24. Suzuki GM, Ohbayashi F, Mita K, Shimada T: The mechanism of sex-specific splicing at the doublesex gene is different between Drosophila melanogaster and Bombyx mori. Insect Biochem Mol Biol 2001, 31(12):1201-1211.
25. Severson WD, Knudson LD, Soares BM, Loftus JB: Aedes aegypti genomics. Insect Biochem Mol Biol 2004, 34(7):715-721.

26. Nene V, Wortman RJ, Lawson D, Haas B, Kodira C, et al: Genome sequence of Aedes aegypti, a major arbovirus vector. Science 2007, 316(5832):1718-1723.

27. Erickson WJ, Quintero Jj: Indirect effects of ploidy suggest $x$ chromosome dose, not the x:a ratio, signals sex in Drosophila. PLoS Biol 2007, 5(12): e332.

28. Clements NA: The Biology of Mosquitoes. London: Chapman \& Hall; 1992.

29. Craig JGB, Hickey AW: In Genetics of Insect Vectors of Disease. Edited by: Wright WJ, Pal R. New York: Elsevier; 1967:67-131.

30. Jurka J, Klonowski P, Dagman V, Pelton P: CENSOR-a program for identification and elimination of repetitive elements from DNA sequences. Comput Chem 1996, 20(1):119-121.

31. Kapitonov W, Jurka J: A universal classification of eukaryotic transposable elements implemented in Repbase. Nat Rev Genet 2008, 9(5):411-412, author reply 414 .

32. Tu Z: Genomic and evolutionary analysis of Feilai, a diverse family of highly reiterated SINEs in the yellow fever mosquito, Aedes aegypti. Mol Biol Evol 1999, 16(6):760-772.

33. Cannon BS, Sterck L, Rombauts S, Sato S, Cheung FF, et al: Legume genome evolution viewed through the Medicago truncatula and Lotus japonicus genomes. Proc Natl Acad Sci USA 2006, 103(40):14959-14964.

34. Cho $S$, Wensink CP: DNA binding by the male and female doublesex proteins of Drosophila melanogaster. J Biol Chem 1997, 272(6):3185-3189

35. Erdman ES, Burtis CK: The Drosophila doublesex proteins share a novel zinc finger related DNA binding domain. Embo J 1993, 12(2):527-535.

36. Ruiz MF, Eirín-López JM, Stefani RN, Perondini AL, Selivon D, Sánchez L: The gene doublesex of Anastrepha fruit flies (Diptera, Tephritidae) and its evolution in insects. Dev Genes Evol 2007, 217(10):725-31.

37. Hughes AL: Runaway evolution of the male-specific exon of the doublesex gene in Diptera. Gene 2010.

38. Gentile C, Lima BJ, Peixoto AA: Isolation of a fragment homologous to the rp49 constitutive gene of Drosophila in the Neotropical malaria vector Anopheles aquasalis (Diptera: Culicidae). Mem Inst Oswaldo Cruz 2005, 100(6):545-547.

39. Goodwin FS, Taylor JB, Villella A, Foss M, Ryner CL, et al: Aberrant splicing and altered spatial expression patterns in fruitless mutants of Drosophila melanogaster. Genetics 2000, 154(2):725-745.

40. O'Connell OP, Rosbash M: Sequence, structure, and codon preference of the Drosophila ribosomal protein 49 gene. Nucleic Acds Res 1984, 12(13):5495-5513.

41. Polito C, Pannuti A, Lucchesi CJ: Dosage compensation in Drosophila melanogaster male and female embryos generated by segregation distortion of the sex chromosomes. Dev Genet 1990, 11(4):249-253.

42. Stanewsky R, Lynch SK, Brandes C, Hall CJ: Mapping of elements involved in regulating normal temporal period and timeless RNA expression patterns in Drosophila melanogaster. J Biol Rhythms 2002, 17(4):293-306.

43. Hempel UL, Oliver B: Sex-specific DoublesexM expression in subsets of Drosophila somatic gonad cells. BMC Dev Biol 2007, 7:113.

44. Gabrieli P, Falaguerra A, Siciliano P, Gomulski ML, Scolari F, et al: Sex and the single embryo: early development in the Mediterranean fruit fly, Ceratitis capitata. BMC Dev Biol 2010, 10(1):12.

45. Inoue K, Hoshijima K, Higuchi I, Sakamoto H, Shimura Y: Binding of the Drosophila transformer and transformer-2 proteins to the regulatory elements of doublesex primary transcript for sex-specific RNA processing. Proc Natl Acad Sci USA 1992, 89(17):8092-8096.

46. Lynch WK, Maniatis T: Synergistic interactions between two distinct elements of a regulated splicing enhancer. Genes Dev 1995, 9(3):284-293.

47. Suzuki GM, Imanishi S, Dohmae N, Nishimura T, Shimada T, et al: Establishment of a novel in vivo sex-specific splicing assay system to identify a trans-acting factor that negatively regulates splicing of Bombyx mori dsx female exons. Mol Cell Biol 2008, 28(1):333-343.

48. Bertossa CR, Zande vd L, Beukeboom WL: The Fruitless gene in Nasonia displays complex sex-specific splicing and contains new zinc finger domains. Mol Biol Evol 2009, 26(7):1557-1569.

49. Verhulst CE, Beukeboom WL, Zande vd L: Maternal control of haplodiploid sex determination in the wasp Nasonia. Science 2010, 328(5978):620-623.

50. Salvemini M, Polito LC, Saccone G: fruitless alternative splicing and sex behaviour in insects: an ancient and unforgettable love story? Journal of Genetics 2010, 89(3):287-299. 
51. Stephens MR, Schneider DT: Features of spliceosome evolution and function inferred from an analysis of the information at human splice sites. J Mol Biol 1992, 228(4):1124-1136.

52. Lawrence CE, Altschul SF, Boguski MS, Liu JS, Neuwald AF, et al: Detecting Subtle Sequence Signals: A Gibbs Sampling Strategy for Multiple Alignment. Science 1993, 262:208-214.

53. Qi J, Su S, Mattox W: The doublesex splicing enhancer components Tra2 and Rbp1 also repress splicing through an intronic silencer. Mol Cell Biol 2007, 27(2):699-708.

54. Heinrichs V, Baker SB: The Drosophila SR protein RBP1 contributes to the regulation of doublesex alternative splicing by recognizing RBP1 RNA target sequences. Embo J 1995, 14(16):3987-4000.

55. Gailey AD, Billeter CJ, Liu HJ, Bauzon F, Allendorfer BJ, et al: Functional conservation of the fruitless male sex-determination gene across 250 Myr of insect evolution. Mol Biol Evol 2006, 23(3):633-643.

56. Gempe T, Hasselmann M, Schiott M, Hause G, Otte M, et al: Sex determination in honeybees: two separate mechanisms induce and maintain the female pathway. PLoS Biol 2009, 7(10):e1000222.

57. Ruiz FM, Milano A, Salvemini M, Eirin-Lopez MJ, Perondini LA, et al: The gene transformer of anastrepha fruit flies (Diptera, tephritidae) and its evolution in insects. PLOS ONE 2007, 2(11):e1239.

58. Saccone G, Salvemini M, Polito LC: The transformer gene of Ceratitis capitata: a paradigm for a conserved epigenetic master regulator of sex determination in insects. Genetica 2010.

59. Fu G, Lees SR, Nimmo D, Aw D, Jin L, et al: Female-specific flightless phenotype for mosquito control. Proc Natl Acad Sci USA 2010, 107(10):4550-4554.

60. Thompson DJ, Higgins GD, Gibson JT: CLUSTAL W: improving the sensitivity of progressive multiple sequence alignment through sequence weighting, position-specific gap penalties and weight matrix choice. Nucleic Acids Res 1994, 22(22):4673-4680.

61. Tamura K, Dudley J, Nei M, Kumar S: MEGA4: Molecular Evolutionary Genetics Analysis (MEGA) software version 4.0. Mol Biol Evol 2007, 24(8):1596-1599.

62. Efron B, Halloran E, Holmes S: Bootstrap confidence levels for phylogenetic trees. Proc Natl Acad Sci USA 1996, 93(14):7085-7090.

63. Nei M, Gojobori T: Simple methods for estimating the numbers of synonymous and nonsynonymous nucleotide substitutions. Mol Biol Evol 1986, 3(5):418-426

doi:10.1186/1471-2148-11-41

Cite this article as: Salvemini et al:: Genomic organization and splicing evolution of the doublesex gene, a Drosophila regulator of sexual differentiation, in the dengue and yellow fever mosquito Aedes aegypti. BMC Evolutionary Biology 2011 11:41.

\section{Submit your next manuscript to BioMed Central and take full advantage of:}

- Convenient online submission

- Thorough peer review

- No space constraints or color figure charges

- Immediate publication on acceptance

- Inclusion in PubMed, CAS, Scopus and Google Scholar

- Research which is freely available for redistribution

Submit your manuscript at www.biomedcentral.com/submit
Biomed Central 